- Eaps Organisation Profile series \#5

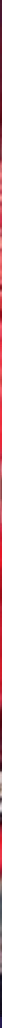

AUTHOR: Bulent Kenes

\title{
CasaPound Italy: The Sui Generis Fascists of the New Millennium
}

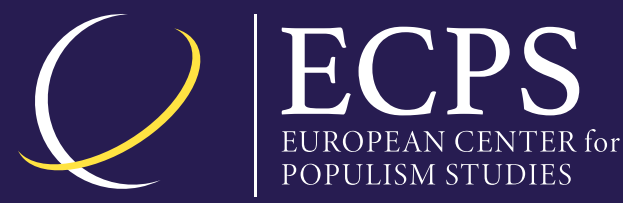




\section{CasaPound Italy: The Sui Generis Fascists of the New Millennium}

BY BULENT KENES

\section{ABSTRACT}

CasaPound Italy is one of the most interesting and ambiguous populist right-wing extremist groups emerged in Europe. Its supporters say they are not 'racist' but are against immigration because of its impact on wages and houses; not antisemitic, but anti-Israel vis-à-vis Palestine; not homophobic, but supporters of the 'traditional family'. Never before there was in Italy an explicitly neo-fascist group enjoying the strategic viability and the marge of political manoeuvre that was secured today by the CasaPound. Although CasaPound remains substantially marginal from an electoral point of view, its visibility in the Italian system is symptomatic of the ability of the extreme right to assimilate populist and alternative agendas in order to increase the attractiveness of their communication campaigns.

BULENT KENES is an academic and a journalist who has over 25 years of professional experience. He has managed multiple publications, both in Turkish and English.

ECPS Organisation Profile Series offer analyses of political leaders and prominent public figures with populist tendencies. Unless otherwise indicated, the views expressed by the author are only attributable him and not to any institution with which they are associated.

The profile available for free downloading from the ECPS website (wwW. populismstudies.org)

(C)ECPS 2021 


\section{Table of contents}

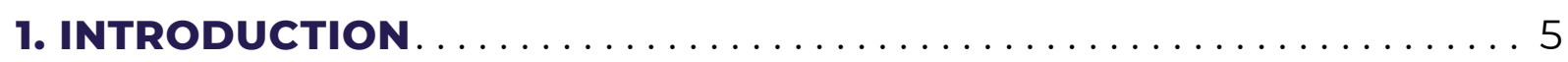

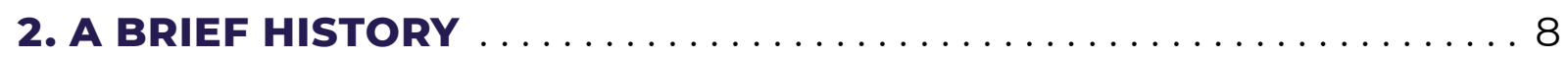

3. CASAPOUND HAS ALREADY FULFILLED ITS MISSION BY NORMALISING FASCISM $\ldots \ldots \ldots \ldots \ldots \ldots \ldots \ldots \ldots$

4. "HYBRIDIZATION" AS AN IDEOLOGICAL CHOICE AND

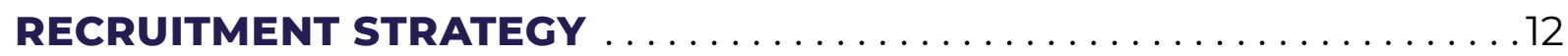

5. "FASCISM À LA CARTE" .............................. 14

6. A POLITICAL PARTY THAT FUNCTIONS TO TRIVIALIZE CONCERNS ABOUT FASCISM

7. A HIERARCHIC AND MERITOCRATIC ORGANISATION

8. MEMBERS: FASCISTS OF THE THIRD MILLENNIUM

9. CPI'S WOMEN: DECONSTRUCTING THE THEORY OF FASCIST MISOGYNY .18

10. HYBRID IDEOLOGY FACILITATES DIVERSIFIED ACTIVITIES .19

11. VIOLENCE AS A METHOD OF DEMONSTRATION AND EXPRESSIVE ACTION. 
12. NEO-FASCISM AS SHOW BUSINESS.

13. ANTI-IMMIGRATION \& ANTISEMITISM

14. CASAPOUND'S TRANSNATIONAL CONNECTIONS

AND IMPACT

CONCLUSION 31

REFERENCES 


\section{INTRODUCTION}

The last two decades have seen the rise of populist right-wing extremism characterized by political campaigning targeting immigration, European integration, and globalization (Castelli Gattinara \& Froio, 2014) and a growth in nationalist, radical populist parties and movements in Western Europe. In the contemporary European Fascist "black galaxy," Italy has been an important incubator and generator of ideas. Italian post-war Fascism "may be seen as the vanguard of right-wing extremism for roughly 40 years." (Mammone, 2015: XIV) CasaPound, as Mammone (2015: 213) describes it, is "the most interesting, and atypical in some ways, right-wing enterprise of these recent years" (Bialasiewicz \& Stallone, 2020).

The majority of these populist, right-wing extremist organisations have been defined by their opposition to immigration and multiculturalism, the effects of international capitalism on workers' rights, and their concern for protecting national and European culture. This is combined with "anti-establishment" rhetoric used to appeal to those who are disillusioned with mainstream political parties, the media, and government. As members of an anti-establishment movement, CasaPound supporters have very low levels of trust in the government, the EU, political parties, trade unions and the press (Bartlett et al., 2012). However, according to Bartlett et al. (2012), these organisations do not fit easily into the traditional political divides; one of the most difficult to classify is CasaPound, which was originally founded in Italy in 2003 but was formalised in 2008 under the name CasaPound Italia (CPI) (Jones, 2018). A "populist" rubric is a staple of new-Fascist politics and CasaPound is no exception: theirs is translated through the rhetoric and material enactment of an "exclusionary welfarism" (Bialasiewicz \& Stallone, 2020).

Today, CPI is the most visible neo-fascist organization in Italy-and probably one of the most visible extreme right movements in Western Europe (Castelli Gattinara \& Froio, 2015). CasaPound's emphasis on nationalism, its welfare chauvinism that privileges ethnic Italians for the receipt of welfare services, and its direct take-to-the-streets approach have made it a member of the "new right" European street-based movements (Bartlett et al., 2012). $\mathrm{CPI}$ has also been central to again normalising fascism in the country of its birth (Jones, 2018). Thanks to CPI, similar extremist organisations and farright populist parties' extremist violence, harassment, and xenophobia reemerged in Italy. Italy's intelligence services have warned about the growing appeal of radical right groups, especially among young people (Povoledo, 2018).

As with other far-right groups, the economic crisis in Europe in the early 2010 s provided CasaPound with fertile ground for spreading its ideas. The crisis allowed the CPI to strengthen its criticisms of international capitalism as well as eurozone fiscal policy. It has also argued against the weakening of 
the nation state and the increasing power of unelected technocrats (Bartlett et al., 2012). CasaPound was born as a single-issue movement as a result of the social problem associated with the lack of housing spaces for Italian families (Castelli Gattinara et al., 2013). Since its origins, CasaPound has stood out for its attention to the issue of affordable housing, engaging primarily in struggles on the social and cultural right to adequate shelter for Italian families (Castelli Gattinara \& Froio, 2015).

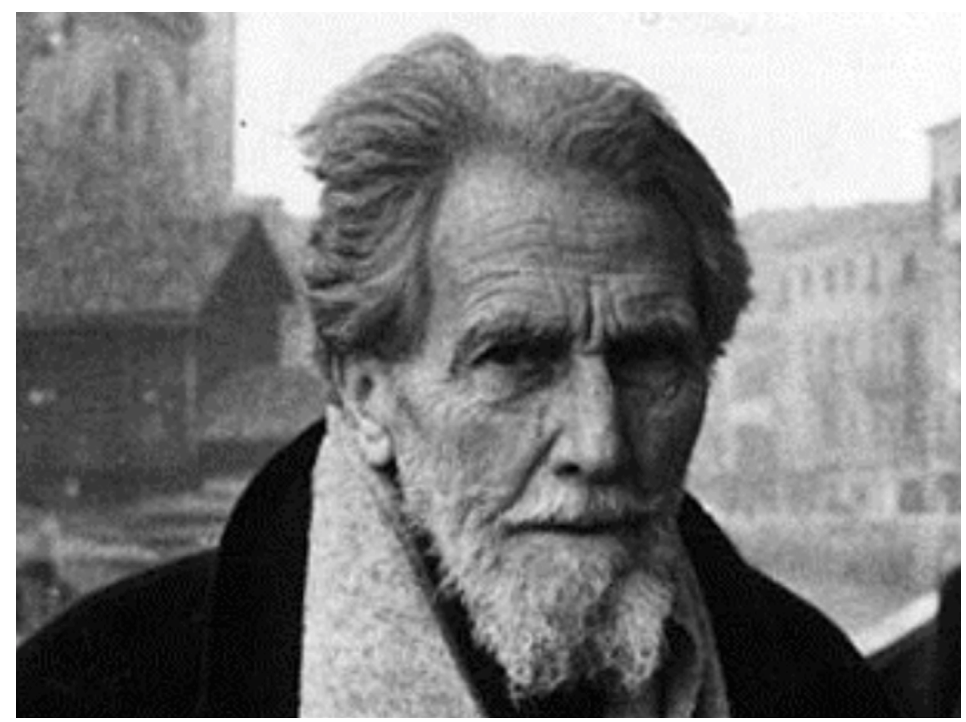

Ezra Pound.

The group's name is composed of two elements: i) "Casa," the Italian Word for "house." The largest number of eviction orders in 2008 were issued in Rome $(7,574)$, among which almost five thousand were for arrearage. During the following five years, the evictions numbered over 31,000 , of which 19,273 were for arrearage. In Rome, the evictions numbered 11,612 (Castelli Gattinara et al., 2013). ii) "Pound," referencing the 20th-century American poet Ezra Pound, who supported Mussolini's dictatorship (Redman, 1991), adhered to the Repubblica Sociale Italiana (Italian Social Republic), and was an antisemite (Kington, 2011; 2012). The organization's name explicitly connects it with one of the pillars of the group's ideology, Ezra Pound's theory of housing rent as "usury" (Pound, 1985), and the poet's views expressed in his poem Canto $\mathrm{XLV}$ opposing rent and rapacious landlords. For the poet, everything that is not used by its owner becomes capital, which is then brought in the market obliging others to pay a monthly tangent: the rent (Castelli Gattinara et al., 2013).

Since its birth, CasaPound has conceptually associated its political engagement to Ezra Pound's conception of "holiness" of the "house." The groups' opposition to market capitalism has to do with this, since the house is given a symbolic value that goes beyond its material price (Castelli Gattinara \& Froio, 2015).

The name CasaPound also has a great symbolic meaning, since Ezra Pound was the incarnation of the ideal fascist revolution, meaning the 
struggle against plutocracy (Redman, 1991; Feldman, 2013). Despite many scholars having demonstrated the influence of the poet's anti-capitalist and anti-communist discourse on CasaPound (Rinaldi \& Feldman, 2015; Lidell, 2012) Ezra Pound's daughter, Mary De Rachewiltz, has repeatedly gone to court to stop CasaPound from using her father's name (Kington, 2011, 2012). "This organisation is hiding behind Pound's name for intellectual cover," De Rachewiltz said and added: "He made mistakes and we have to take the good part of him, just as he did with others. He fell into certain antisemitic clichés that were rampant in Europe and the US at the time." Pound later told the American poet Allen Ginsberg that his worst mistake in life was his "stupid suburban antisemitic prejudice" (Kington, 2012). 


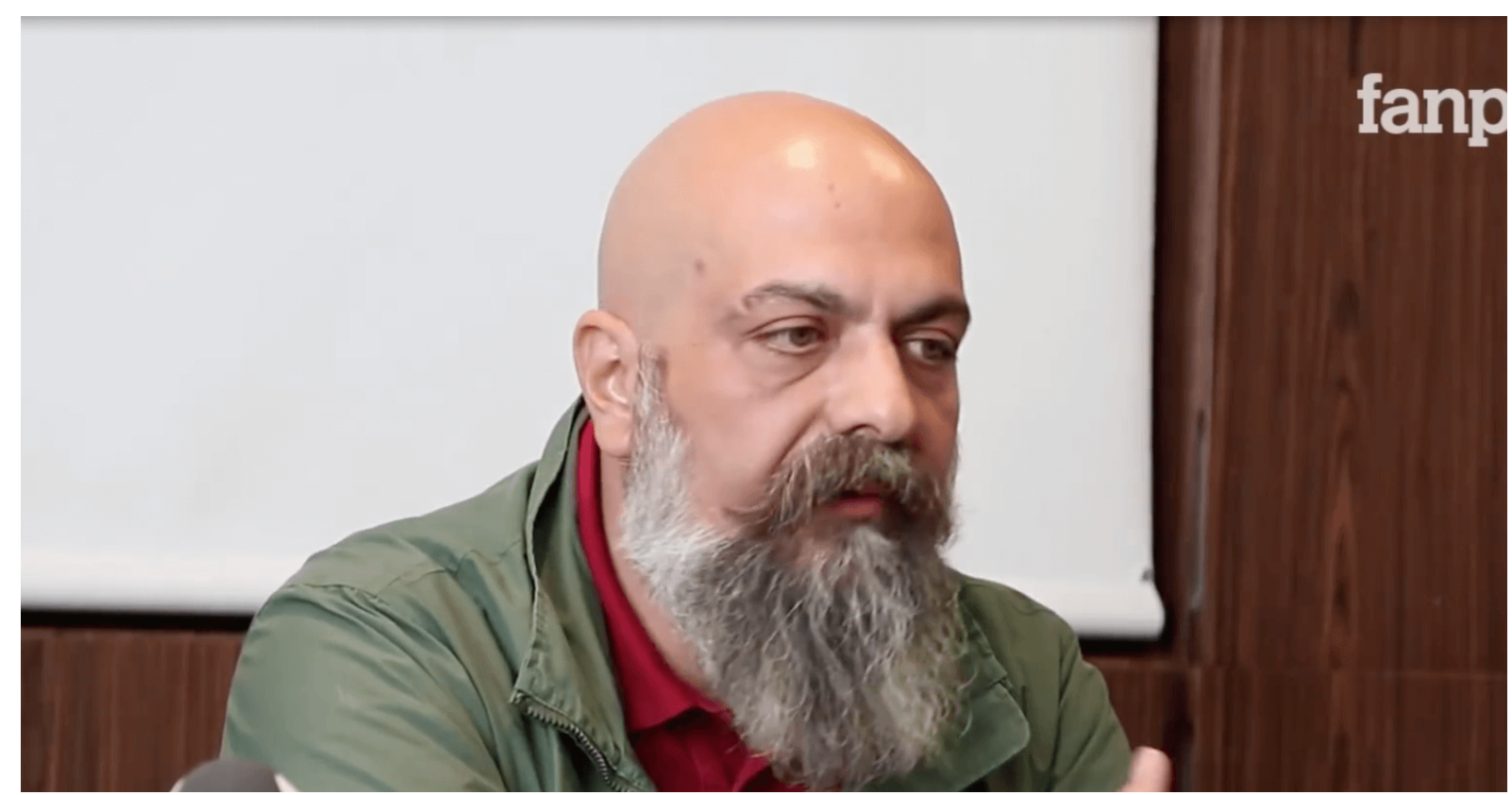

Gianluca lannone.

\section{A Brief History}

CasaPound was born as a youth organization on December 26, 2003, in Rome, during the occupation of a building in the Esquilino district, a multiethnic neighbourhood populated mostly by Chinese and Bengali people (Gretel Cammelli, 2018). On that night, five men broke into a huge, state-owned, empty office complex. According to the story of the seizure of the building, which is now part of the group's origin myth (Bialasiewicz \& Stallone, 2020), a few days earlier, the men had put up fake fliers, appealing to the public for help to find a lost black cat called "Ezra." It was a way to avoid suspicion as they surveyed the building before breaking in. Nothing was left to chance: the date, between Christmas and New Year, was chosen because there wouldn't be many people around. Even the name and colour of the cat wasn't casual: "Ezra" was a nod to the American poet; black was the colour associated with their hero, Benito Mussolini (Jones, 2018). While the details may differ, the repetition of this narrative very usefully serves the purpose of mythmaking. Multiplied by the attention of media, CasaPound has been able to frame a Fascist archetype, creating an at once folkloric and banal construction of "the neo-Fascist" (Bialasiewicz \& Stallone, 2020).
CasaPound was founded as a branch of the Fiamma Tricolore (FT) party of Pino Rauti, making specific reference to the history of the post-war neo-fascist party Movimento sociale italiano (MSI, Italian Social Movement, which was founded on December 26, 1946) and Mussolini's legacy. The occupation on the same day was not accidental, since it furnished an explicit initial link between the CasaPound movement and the fascist era and its legacy (Gretel Cammelli, 2018).

The man giving orders that night was Gianluca lannone (1974-), who came from a more "old style" Fascist activism (Bialasiewicz \& Stallone, 2020). Then 30, lannone had "me ne frego" ("I don't care" - the slogan used by Mussolini's troops) tattooed diagonally across the left side of his neck (Jones, 2018). At the beginning of the third millennium, lannone already had an interesting career behind him as member of a minor extremist extra-parliamentary right-wing group which was dissolved by law in the 1990s for hate-speech and racism. In 1995, he had been one of the founders of the Rupe Tarpea Produzioni, an independent record company that produced, and still produces, Nazi rock groups such as Hobbit, Intolerance, etc (Jones, 2018).

In 1997, lannone founded the rock band ZetaZeroAlfa (ZZA), which gave voice to concerns that had been disregarded by 
established parties of the radical right: housing, globalization, and the need to revolt against the establishment (Castelli Gattinara \& Froio, 2014). ZZA became an evangelising force for fascism. Touring all over Italy, the band sang raucous punkrock songs with lyrics such as, "I love this proud people / that doesn't know peace." However, the song that became a crowd favourite was Cinghiamattanza, meaning "death by belt": at all the gigs, it became a ritual for fans to take off their belts and lash each other (Jones, 2018).

lannone was also one of the leaders of the Romanist hooligans, the animator of the fascist pub Cutty Sark which was a meeting point for Rome's extreme right, and the owner of the "non-conventional" bookshop Testa di Ferro in Rome, which disseminated nostalgic fascist literature. Armed with charisma and a strong reputation, lannone became the leader of the "right-wing" house occupations in Rome (Wolff, 2019; Jones, 2018).

The men gathered together and hugged, feeling that they had planted a flag in the centre of the Italian capital-in a gritty neighbourhood which was home to many African and Asian immigrants. lannone dubbed their building "the Italian embassy." The building became the headquarters of the movement called CasaPound (Jones, 2018). In this building, which is still occupied by activists, there are three apartments per floor that host the activists and 23 families. The police did not intervene at the time of the occupation, nor did they act in the following months or years. Successive mayors of Rome have treated the fascist occupation with a degree of tolerance (Gretel Cammelli, 2018).

Actually, it was not the first building that was occupied by the group. In 2002, CasaPound occupied a state-owned building in Rome and established the so-called "Casa Montag." The name came from Guy Montag, the protagonist of Ray Bradbury's science fiction novel Fahrenheit 451 (1953). Indeed, Bradbury's critique of a totalitarian state was transformed into Casa Pound's intolerance against anti-fascism in Italian politics. CasaMontag became the first example of right-wing Occupazioni Non Conformi (ONC, or Non-Conventional
Occupation), which aimed to use musical events to get young people to discuss politics in a non-structured way (Wolff, 2019).

\section{CasaPound Has Al- ready Fulfilled Its Mission by Normalis- ing Fascism}

Initially, Casa Montag did not have a real political and communitarian aim but was a centre for people to meet, socialise, play music, and discuss political and social issues. The squatting inside Casa Montag and subsequent building occupations had the primary goal of housing Italian families that lost their houses and protesting against the rising rents in Rome and related real estate speculations: the group's slogan was "rent is usury: stop the increasing costs of living" (Bartlett et al., 2012). lannone has called usury "the worst thing... the head of the octopus... which creates unemployment, debt and threatens the future of our children" (Lidell, 2012). CasaPound argues for a form of "social mortgage" (mutuo sociale)—a housing policy that would guarantee all Italian workers the right to own a property; the right of home ownership is crucial to the movement's message (Bartlett et al., 2012).

Only one year later, in 2003, lannone led the expedition that occupied the building in via Napoleone: CasaPound. That squat occurred under the slogan "Occupazioni a Scopo Abitativo" (OSA: Occupations for Housing Purposes). Several others followed. Many make a clear distinction between ONC and OSA, arguing that the former has a metapolitical nature while the latter has a social purpose (Wolff, 2019). The concern for housing is the core of CasaPound's ideology and policy and is reflected in the group's name as well as its use of the turtle as its main logo: "The turtle is one of the few living beings which is fortunate enough to have with them the house" (Bartlett et al., 2012). The stylized turtle symbol also refers to the Roman formation called Testudo, the army of Rome that showed the greatness and force of 
the Empire and which emerged "from a vertical order and from a hierarchical principle." Contextually, the octagonal shape is reminiscent of the historical monument Castel del Monte, built by the "last Cesare" in Italy. The arrow is the same as that in the flags of other far-right movements across Europe (Wolff, 2019).

From 2006-2008, lannone was active as leader of a youth group in the FT trying to conquer the party's leadership-without success (Wolff, 2019). In 2008, CasaPound, whose activists define themselves as "third millennium fascists"(Gretel Cammelli, 2018; Bulli, 2019), broke off from the FT to become an officially registered association with offices in all major Italian cities under the name CasaPound Italia (CPI). As a legally recognized association, CasaPound was eligible to receive voluntary pre-tax donations (Gretel Cammelli, 2018). CPI openly rejects left-wing and right-wing labels, and distances itself from traditional parties and has instead rooted itself in the tradition of Italian Fascism (Castelli Gattinara \& Bouron, 2020).

Starting from 2011, however, CPI regularly took part in local and national elections, and progressively expanded its programmatic agenda on socioeconomic affairs. At first, its candidates ran as independents within centre-right coalitions (Pirrò \& Castelli Gattinara, 2018). In 2013, it developed a new strategy as an independent political party and participated in local elections in February (Gretel Cammelli, 2018). CPI's evolution is also reflected in changing electoral slogans between 2013 and 2018: from "Direction Revolution" to "Direction Parliament" (Pirrò \& Castelli Gattinara, 2018).

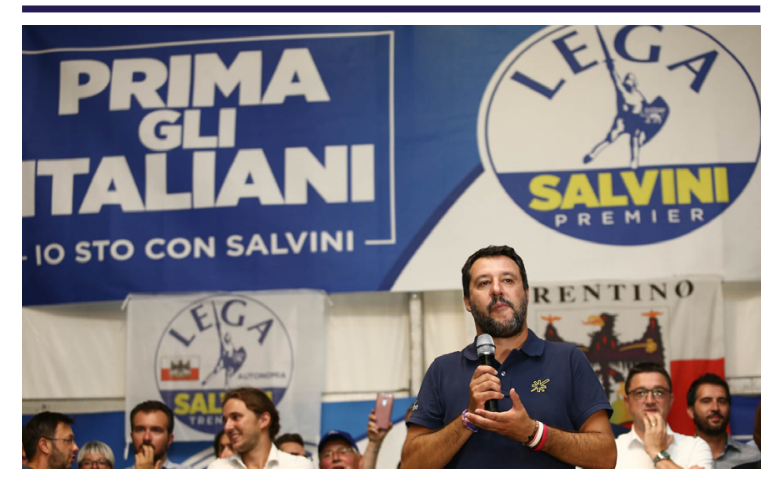

Matteo Salvini, Head of the Lega Nord (Northern League) party and former Interior Minister. Photo: Pierre Teyssot.
While the results at the national level have been poor (0.14 percent in 2013), CPI won 0.69 percent of votes in Lazio, comprising 8,734 votes in the city of Rome. In 2014, it struck up informal relations with the Lega Nord (LN) and contributed to the election of an $L N$ candidate to the European Parliament (EP). In 2015, a new political formation called Sovranità established an alliance between the two parties supporting the LN's leader Matteo Salvini and secured the election of its own officials to local councils. In 2016, CasaPound participated in the elections as an independent party, winning 1.14 percent of the vote in Rome, equivalent to around 14,000 votes. In the 2017 local elections, CPI scored results above five percent and elected council members in different municipalities within Central Italy. Moreover, a former member has been elected mayor of L'Aquila as part of a right-wing list (Pirrò \& Castelli Gattinara, 2018; Gretel Cammelli, 2018).

Italy's political panorama is defined not just by radical right-wing parties, which received considerable support by voters during elections in March 2018, but also by the presence of extra-parliamentary organizations that increasingly engage in the public debate by presenting radical arguments and propositions. One of these is CasaPound Italia (Wolff, 2019). CPI ran with an independent list in the local and national elections. On this occasion, CPI failed to elect any candidates to parliament (winning a meager 0.9 percent of votes), yet doubled its electoral support compared to the previous national elections-from 50,000 to about 130,000 votes (Pirrò \& Castelli Gattinara, 2018; Gretel Cammelli, 2018). The results of the 2018 elections were a shock to the Italian political establishment, delivering a historical blow to the parties of the centre-left; the feared entry of the neo-Fascists into Parliament did not materialize, however (Bialasiewicz \& Stallone, 2020).

Nevertheless, CasaPound has already fulfilled its mission by normalising fascism in Italy. At the end of 2017, II Temponewspaper announced Benito Mussolini as its "person of the year." It wasn't being facetious: II Duce barged into the news agenda every week of the year. Even a left-wing politician in Florence said that "nobody in 
this country has done more than Mussolini." More than 75 years after his death, he is more admired than traditional Italian heroes such as Giuseppes Garibaldi and Mazzini. Moreover, in just 15 years, CasaPound has grown so large that its initial ambition-to be accepted into the theatre of "open debate"-is now obsolete. Instead, its leaders now talk of eradicating anti-fascism entirely. Fascism, lannone enthuses, was "the greatest revolution in the world, the completion of the Risorgimento [Italian unification]." Mussolini's regime was "the most beautiful moment of this nation" (Jones, 2018).

Meanwhile, an Italian judge ordered police on June 4, 2020, to seize CasaPound's headquarters in a move hailed as a victory by the city's mayor Virgina Raggi from the anti-establishment 5 Star Movement (M5S). The order to seize the building, issued on the 76th anniversary of Rome's liberation from Nazi occupation by US troops in World War Two, has not yet been carried out (Reuters, 2020), because the government has temporarily halted evictions as a result of the coronavirus pandemic (Roberts, 2020). 

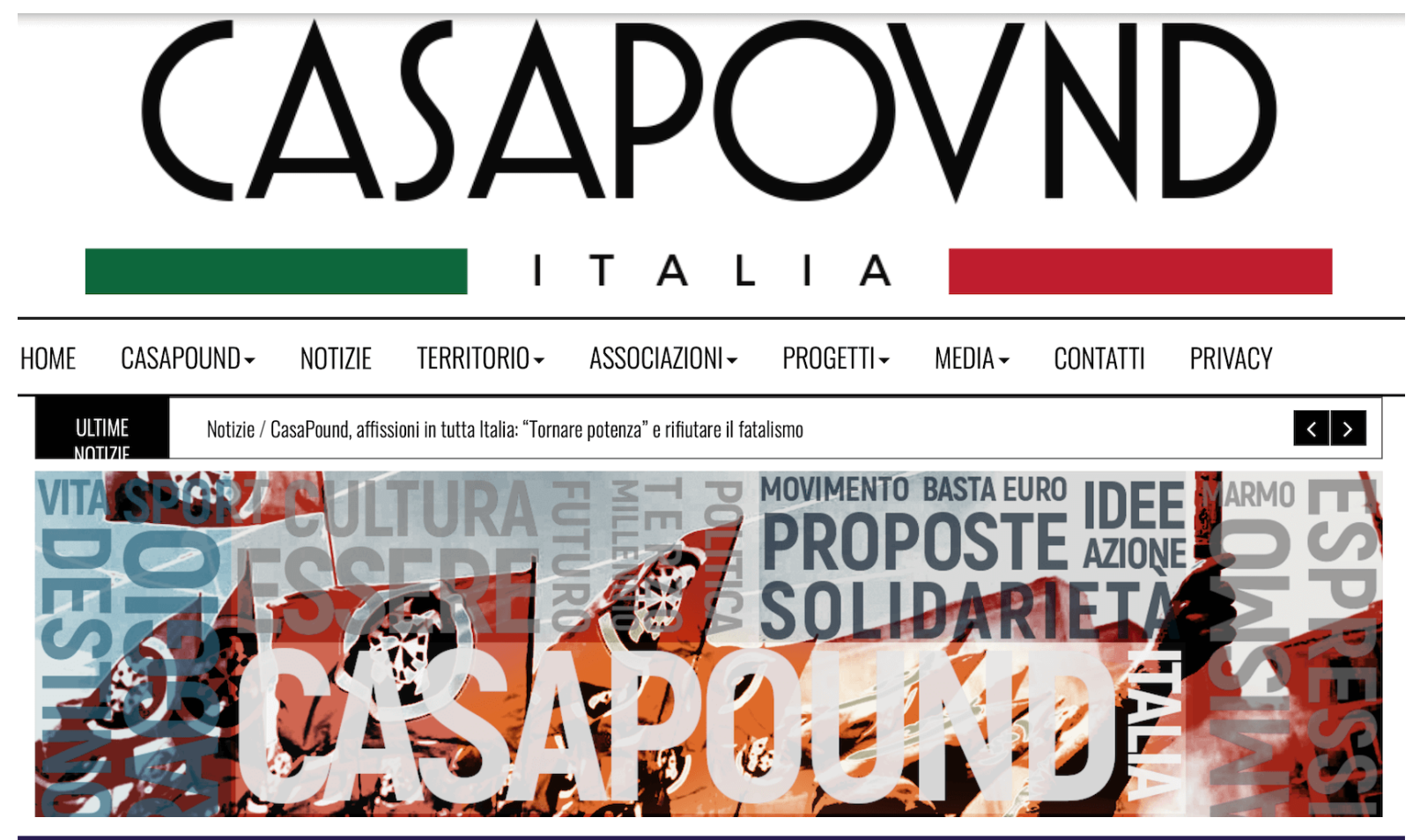

"Hybridization" As an Ideological Choice and Recruitment Strategy

At the beginning of the 1990s, a new phase in the Italian party system was ushered in with the inclusion of a post-Fascist party, Alleanza Nazionale (AN, National Alliance), in centre-right coalitions. This normalization at the party level did not occur in the same way at the subcultural or grassroots level (Bulli, 2019). Though "apologizing for fascism" was still a crime in Italy (Wolff, 2019), for Italy's modern neo-fascist groups like CasaPound, II Duce was-and is-very much about ideology. According to CPI's vice-president, Simone di Stefano, CPI's youngsters already see Mussolini as the country's father (Kington, 2013). In addition, the rise of populism, and CPI's explicit rejection of traditional right and left categories, has changed the landscape of party politics and affected political movements, especially those of the far right. During this period, a symbolic hybridization between the far-right and the far-left (Miller-Idriss, 2018) and nostalgia defined CPI's recruitment strategy
(Bulli, 2019).

This hybridization manifests itself even in the entrance hall of CPI's headquarters. CasaPounders painted a hundred or so men's names, suggesting their ideological lineage. Many were obvious-Mussolini, Oswald Mosley, Nietzsche, war criminals like Hamsun, Degrelle, the writer and proto-fascist Gabriele D'Annunzio, the Italian fascist philosopher Julius Evola-but many more were bizarre or delusional: Homer, Plato, Dante, Kerouac, Ray Bradbury, as well as Ahmed Shah Massoud (the Afghan jihadi leader), and even cartoon characters such as Captain Harlock and Corto Maltese. "Delusional" because most of these characters are more frequently seen as representing liberal and progressive values, and "bizarre" because CasaPound mobilizes the "other" as representative of Fascist thought (Bialasiewicz \& Stallone, 2020; Jones, 2018).

Drawing on populism, expressionism, and pluralism, as a fascists movement $\mathrm{CPI}$ creates political orientations that defy easy placement along a right-left axis (Bialasiewicz \& Stallone, 2020). By adopting symbols, dress codes, and participation models typical of the extreme left, CPI shows its indifference to the codification of rituals according to a left-right understanding of politics. From this perspective, 
the group tries to differentiate itself from the "neither right nor left" rhetoric of the New Right and from the "aesthetics of the 'Third Way' of Italian Fascism" (Ben-Ghiat, 1996). Despite CPI being commonly placed in the category of the Italian radical right, at the rhetorical level the group asserts differences from traditional radical-right parties (Castelli Gattinara \& Froio, 2014).

However, all the elements that make up the multifaceted cultural imaginary of CasaPound originate from the ideology of Fascism, including its cultural manifestations, its exaltation of the masculine body, virility, and speed of action, and its concept of "lifestyle" (Bulli, 2019). In this context, $\mathrm{CPI}$ refers mostly to the social and labour legislation during the Fascist regime: the Labour Charter from 1927, the Verona Manifesto from 1943, and in general all documents that testify to the fascists' engagement in social policy, corporatism, and socialization (Wolff, 2019). The party strategically downplays the most stigmatized aspects of Fascism, such as antisemitism and racism (Castelli Gattinara et al. 2013; Castelli Gattinara \& Froio, 2014).

CasaPound accepted that the racial laws of 1938, which introduced antisemitism and deportation, were "errors." The movement claimed to be "opposed to any form of discrimination based on racial or religious criteria, or on sexual inclination" (Jones, 2018). Despite its realignment with the xenophobic, law-and-order and nationalist agendas of most radical-right populist parties since 2014 , CPI tends to distinguish itself from Italian parties of the extreme right by underlining its anti-establishment character (Gattinara, Froio, \& Albanese, 2013) in an effort to create a political traditionalism that coexists with an open challenge to all forms of pre-defined belonging (Bulli, 2019). Even if CPI claims its origins in Italian Fascism, it builds its political message on the framework of "metapolitics" - a Gramscian approach to politics, in which cultural change and hegemony precedes political change (Wolff, 2019). Namely, unlike other radical-right organizations in Western Europe, the bulk of CasaPound's policy positions, ideas, and practices revolve around economic and social areas (Castelli Gattinara et al., 2013) and are directly inspired by the leftist current that has always existed in Italian Fascism and neo-fascism. In particular, three major concepts that connect CasaPound to three different tendencies of neo-fascism should be highlighted: the Destra Sociale (Social Right), the spiritualism of Ordine Nuovo (New Order), and the tradition of the Nouvelle Droite (New Right) (Castelli Gattinara et al., 2013),

The Destra Sociale was a group internal to the MSI and connected directly with the experience of the Italian Social Republic. Partisans of this political trend stressed the "socialist" aspects of the fascist doctrine, clamouring for a strong state able to take care of its citizens from the cradle to the grave. Similarly, CasaPound calls for a stronger state to protect citizens from the "dictatorship" of the banks and the international financial system (Castelli Gattinara et al., 2013).CasaPound also takes direct inspiration from Italian Fascism in its restless fight against international capitalism. The reference here is to Mussolini's attacks against the international plutocracies which were held responsible for the destruction of national economies (Castelli Gattinara et al., 2013). CPI has also opposed Italy's austerity programme, most notably in the campaign "Ferma Equitalia" ("Stop Equitalia"). Equitalia is the public company in charge of the collection of taxes and the Italian symbol of the austerity movement. Since the beginning of 2012, different bases of Equitalia have been the target of several bomb attacks (Bartlett et al., 2012).

Among the 18 points of CPI's political programme, the first calls for the "public control of banks." The nationalism and autarchy of CPI is characterized by an aversion to all multinational corporations and European institutions (Gretel Cammelli, 2018). The state is also supposed to be "ethical, organic and inclusive" and "something spiritual and moral" aimed at ensuring that the nation remains independent of private and international interests. Society was seen as an "organism" in which individuals were merely tools for pursuing the interests of society as a whole (Gretel Cammelli, 2018).

Ordine Nuovo was founded in 1956 by Pino Rauti and other militants of the MSI. 
They disagreed with the party on a number of grounds, including the recognition of NATO. The group developed a strong cultural commitment but also a sense of militancy where particular importance was given to violent actions against opponents. Numbers of its militants have been accused of terrorist activities (Castelli Gattinara et al., 2013). Finally, CasaPound inspires parts of its ideology from the experience and practice of the Nouvelle Droite of Alain de Benoist.

Together with the Nuova Destra, these were among the most interesting political experiments of the 1970s. Following the protest movements begun in May 1968 in Paris, intellectuals tried to renovate the right wing, emphasizing or adding issues such as federalism and ecology, but also an ethnic-identarian vision, communitarism, anti-imperialism and Europeanism (Mammone, 2008).

In line with the aforementioned ideological debate, CPI's self-styled revolutionary fascist members have declared themselves to be "the fascists of the new millennium" (Wolff, 2019). The group has voluntarily embraced this label as effectively portraying the mixture of Fascist traditionalism with the promise of the future and a contemporary ethos. As Mammone (2009: 187) observes, CPI exemplifies "a modern blackshirt Janus with one face looking backward and the other forward towards the future." The label also emphasizes the adaptation of a classic extreme-right movement to a fast-changing environment in which language, communication, and behaviour play a role comparable to values and ideology, thus creating a cultural imaginary suitable for the political mobilization of new members (Forchtner \& Kølvraa, 2017).

\section{"Fascism à la Carte"}

The CPI's success at recruiting new members derives from: i) Its variable approach to a new form of political identification. This consists of both a "strong" approach, allowing for a conceivable return to codified traditions and symbols of Fascism, and a "soft" attitude towards the strategic selection of symbols, metaphors, topoi, and fallacies from a wide repertoire (Reisigl, 2008). ii) Its professionalized use of political language to encourage both the embrace and rejection of an ideological understanding of politics. iii) Its mixed use of symbols and the connected cultural imaginary (Bulli, 2019).

CPI's ideology has been described as "fascism à la carte" or "à la carte Fascism" (Albanese et al., 2014), indicating the movement's adoption of only certain elements of Fascist ideology and making use of them to recruit members. CPI selects those elements of the Fascist tradition it finds useful for the clear definition of its own political raison d'être in ideological and social terms. However, quite often CPI ends up taking contradictory positions in order to accommodate the needs of different audiences. "Fascism" remains the backbone by which the group substantiates its criticism of supranational institutions, globalization, and the establishment; yet, CasaPound approaches it by making a strategic mix of different elements depending on the issues that are debated, selectively emphasizing some relevant aspects, and omitting others (Castelli Gattinara \& Froio, 2015).

Meanwhile, contextualizing its increasing popularity following the 2008 financial crisis, CPI's position has been outlined as the typical third-wayism: "The refusal of neoliberal economic theories and the neo-nationalist defence of workers' rights." However, less attention has been paid to CPI's Euroscepticism, anti-globalism/mondialism, anti-Zionism, and racism. These have manifested as cultural racism; nationalism based on identarian discourse (ethno-nationalism); "welfare chauvinism;" exclusionary nationalism,; rejecting a multi-racial society; the defence of ethnic identities; opposition to immigration; a desire to exit from NATO and to remove 
Italy from the US sphere of influence; a quest to nationalize strategic economic sectors; and a fight against "usury" and for the cancellation of public debt (Wolff, 2019).

CPI's political discourse reproduces the nationalist and anti-imperialist features of Italian Fascism. In this sense, the financial crisis directly originates from the contradictions of capitalism and its "wild" economic regime, which CasaPound would instead control by means of a strong state capable of avoiding the inequalities of the market economy. The strong state would also regain the national sovereignty that has been given up in favour of transnational organizations, in particular the EU, the IMF, and the ECB (Castelli Gattinara et al., 2013)

Despite these stances, the group is keen to use symbols and practices that are generally considered distant from the culture of the extreme right culture. This appropriation is also applied to figures and practices traditionally associated with left-wing culture (Castelli Gattinara \& Froio, 2015).

The ideological pillars of CasaPound's view of the economy are also reminiscent of the Weimar's campaigns of economic supremacy and Italian ambitions for food production self-sufficiency in the 1930s. Economic self-sufficiency is a way to reconnect with nature, and this bucolic image of naturalism is not new to radical-right organizations. In this sense, CPI builds a discourse around natural order which affects the environment but also the economy and society at large: a societal ecology (Castelli Gattinara et al., 2013). Thus, CPI emphasizes its organic understanding of national identity and state sovereignty and legitimacy, conceived as natural expressions of the Italian nation: "The Italian nation needs to become once again a national organism with powerful and long-lasting life, aims and means of action, which are well above those of its single or grouped individuals" (Castelli Gattinara \& Bouron, 2020).

The CPI, which adopts "welfare chauvinism" and "welfare populism" (Bialasiewicz \& Stallone, 2020), also uses the concept of ethnopluralism to attain ideological coherence. Ethnopluralism offers a consistent framing of core themes-like social welfare and globalization-as well as issues considered of secondary importance, like gender and the environment. Hybridization thus allows CPI to emphasize its ideological roots in the tradition of the extreme right, while avoiding stigmatization as being outdated or openly racist (Castelli Gattinara \& Froio, 2020). Unlike other far-right movements and parties in Europe for which immigration is the key issue, CasaPound's policy positions cover a range of economic and social areas (Bartlett et al., 2012).

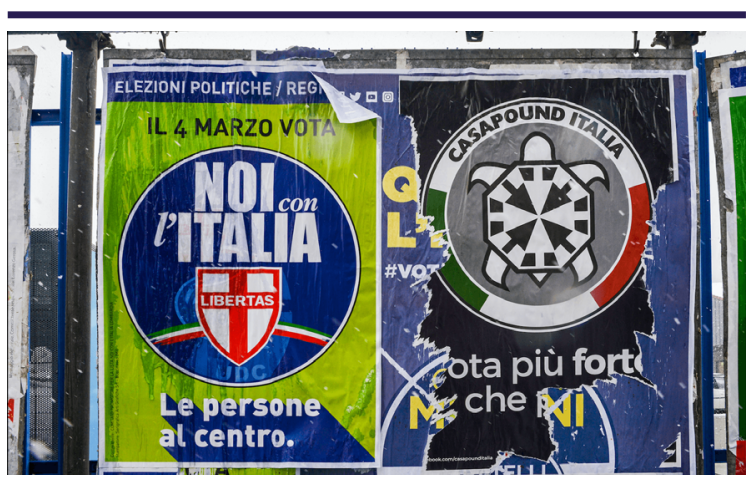

Election posters on billboard ahead of Italian General Election on March 4, 2018.

Photo: Alexandre Rotenberg.

\section{A Political Party That Functions to Trivialize Concerns About Fascism}

The social movement rhetoric and engagement in disruptive forms of protest did not prevent CasaPound engaging in institutional politics. Starting with the 2011 elections, CasaPound presented their candidates in local elections in civic lists or on the centre-right and succeeded in electing its representatives (Castelli Gattinara \& Bouron, 2020). The CPI leadership also announced in October 2012 that it would participate in the local elections in Rome and Lazio, and subsequently in the national elections with an autonomous list of candidates. This came as a surprise to many observers who had underlined the non-electoral nature of CasaPound's 
activism (Castelli Gattinara \& Froio, 2015). Since 2013, CPI has regularly taken part in elections with its own electoral lists (Castelli Gattinara \& Bouron, 2020). However, the choice did not prove particularly successful in the first elections, when CPI won only 0.14 percent of the vote for the Italian House and Senate, and less than one percent in the municipal and regional elections in Rome. However, the success of extreme right actors is not exclusively related to their immediate results. According to the "contagion effect" literature, contemporary extreme right activism strives for the radicalization of mainstream values and political agendas more than for an immediate transformation of the status quo (Lubbers, 2001; Minkenberg, 2001).

CasaPound's electoral participation contributed to further increasing the visibility of the group as well as its reputation as the main non-partisan actor mobilizing on the issue of national sovereignty, as well as its opposition to austerity and the EU. As a consequence, the subsequent months saw an unprecedented electoral alliance between CasaPound and the regionalist populist party Lega Nord (Albertazzi \& McDonnell 2005). This unofficial electoral cartel was first tested in European Parliament (EP) elections in May 2014, when CasaPound explicitly supported one of Lega's candidates (Castelli Gattinara \& Froio, 2015).

In November 2018, the election in the Roman suburb of Ostia was considered by the Italian media as "a test" for the affirmation of CPI in Italian political life. CPI got 9 percent of the votes and obtained one seat in the local municipal council (Torrisi, 2018). In the March 2018 national elections, the CPI obtained 0.94 percent of the vote $(310,793$ votes) but it couldn't enter parliament. CPI's electoral support of the euro-sceptical and xenophobic Lega under the leadership of Matteo Salvini in 2018 influenced public discourse to such a degree that its slogan "Prima gli italiani!" (Italians first!) became the slogan for Salvini's party (Wolff, 2019).

In order to participate in the $2019 \mathrm{EP}$ election, an electoral list was formed by CasaPound and United Right. CasaPound leader Simone Di Stefano topped the list; however, the coalition was unable to win any seats in the EP.

CPI has never won a seat in the national parliament or the EP, but the group has successfully made extreme-right themes more routine in the public sphere, trivializing concerns about historical fascism and racial discrimination (Castelli Gattinara et al., 2013). Nevertheless, on June 26, 2019 , CasaPound's leader lannone announced CasaPound was no longer a political party; instead, the group would return back its original status as a social movement.

\section{A Hierarchic and Meritocratic Organisation}

\begin{abstract}
Although the Italian Constitution bans "the reorganization in any form of the dissolved Fascist Party," CasaPound, like other neo-fascist movements, has skirted the law by identifying as the descendants of Mussolini (Horowitz, 2017). In terms of its organisational structure, CasaPound opted for a strategy of differentiation in order to carve out a space for itself within the extreme right milieu. In this sense, the main goal of CasaPound has not been the development of a concrete organizational alternative for extreme-right activism, but rather the promotion of a claim of generic "otherness" from all existing political organizations (Castelli Gattinara \& Froio, 2015).
\end{abstract}

The organization of CasaPound is hierarchic and meritocratic. Those who work the most, who are most capable to commit, are recognized as leaders-and followed. The leadership is officially embodied by lannone, who is a widely recognized figure in the subcultural milieu of the Italian extreme right. His involvement in the everyday politics of CPI has, however, decreased over time; most of the ordinary business is delegated to the vice-president, who acts as spokesperson and runs as candidate in national and local elections (Pirrò \& Castelli Gattinara, 2018). On November 13, 2017, Simone Di Stefano was elected secretary and nominal prime ministerial candidate for the 2018 general election. 
The internal structure, decision-making, and recruitment does not fully conform to either the model usually followed by electoral actors or that of grassroots organizations. Rather, it combines formal and informal features, hierarchical procedures, and spaces of socialization, merging the organizational practices of social movements with those of formal political parties (Castelli Gattinara \& Froio, 2020). All strategies and policy proposals are decided upon by the inner leadership in Rome and communicated to members, militants, and local branches. Decentralized grassroots initiatives are also possible and welcome but have to be ratified by the offices in Rome. Political activities are further differentiated through separate organizations with thematic responsibilities. There are groups in charge of social voluntary work (e.g., health, workers' rights, the environment), ideology and propaganda (including a daily paper, web radio, and web TV), and specific campaigns (Pirrò \& Castelli Gattinara, 2018). The leader creates or displaces social movement practices and accompanies virtually all actions that can be associated with CasaPound. In addition, personalization takes place through the systematic exhibition of symbols that can be immediately associated with the group (Castelli Gattinara \& Bouron, 2020).

CPI has its headquarters in Rome and branches in other northern and southern cities (Bulli, 2019). The building, which sits incongruously in the heart of an immigrant neighbourhood, has served as CasaPound's home since it was occupied (Horowitz, 2017). In 2006, the movement that arose around the first community centre gained with its student organization, the "Students' Block" ("Blocco Studentesco"). Blocco Studentesco is a mainstay in Rome youth politics, winning 11,000 votes in school council elections in 2009 (Kington, 2013). A fascist women's movement, Tempo di Essere Madri ("time to be a mother"), was founded by lannone's wife. A pseudo-environmental group, La Foresta Che Avanza, began to put "the regime into nature" (Jones, 2018). Among the many groups directly linked to $\mathrm{CPI}$ is the "Circolo Futurista" ("Futurist Circle"), an association devoted to the organization of cultural events (Bulli, 2019).
As of December 2017, CPI had 106 headquarters/local offices across Italy (Wolff, 2019) and lannone described each new centre as a "territorial reconquest." Because every centre was self-financing, and because they claimed to "serve the people," those new centres in turn opened gyms, pubs, bookshops, parachute clubs, diving clubs, motorbike clubs, football teams, restaurants, nightclubs, tattoo parlours, and barbershops. CasaPound suddenly seemed everywhere, echoing the influential fascist philosopher Giovanni Gentile, who wrote in 1925 that fascism was "before all else a total conception of life" (Jones, 2018). Today, CasaPound is present in virtually all Italian regions. It owns fifteen bookshops, twenty pubs, a web radio station (Black Flag Radio) and a web TV channel (TortugaTV). CasaPound also produces publications such as the monthly journal L'Occidentale and the quarterly Fare Quadrato (Castelli Gattinara \& Froio, 2014).

\section{Members: Fascists of the Third Millennium}

CPI has made enormous improvements in terms of recruitment during the last years (Wolff, 2019). CPI members, who define themselves as "Fascists of the Third Millennium" (Bulli, 2019)—complete with black boots, tattooed necks, and shorn hair-guard floors decorated with pictures of Fascist-era marches and banners reading "Arm Your Soul." The members exhibit fondness for Roman salutes and mythic glory days (Horowitz, 2017). Members are referred to as a "camerata" (the fascist version of "comrade") and exchange the old-fashioned "legionary" handshake, grasping each other's forearm rather than the hand (Jones, 2018). Members of CPI's grassroots associations do not always declare their political allegiance, thus facilitating the recruitment of new members. Often, in fact, their first contact with the movement is not an ideological one (Bulli, 2019).

It is important to underline that CPI does not envisage membership without active militancy; becoming a member entails active participation in the events 
and activities promoted by the group. The selection of members follows very strict, yet informal, criteria, and generally occurs by co-optation. After being introduced to the group by other militants, prospective members are invited to public events and activities organized by CPI, "as a way to test their motivation, before introducing them to the circuit of real militancy." Sympathizers unable to become active militants can be appointed as "web supporters" in charge of promoting CPI's messages, images, and activities online. CPI does not have staff or employees on its payroll, and elected officials are required to devote most of their emoluments to the organization (Pirrò \& Castelli Gattinara, 2018).

Although membership in CPI is considered on the rise, it is difficult to rely on declared figures. While the founding group included a few dozen individuals, data from CPI's official website claimed over 2,000 members in 2008 (Pirrò \& Castelli Gattinara, 2018). In 2011, it was estimated that CPI had 5,000 members, while in 2017, the group reached 6,000. As of January 2018, the Facebook account CasaPound Italia had 230,000 followers (Wolff, 2019). CasaPound Facebook supporters were slightly more likely to be unemployed than the average Italian citizen (11 percent vs 7.9 percent) (Bartlett et al., 2012).

\section{CPI's Women:}

\section{Deconstructing the Theory of Fascist Misogyny}

The common assumption that fascism is a misogynist ideology which has tended to exclude women, has been contrasted with cases of women's active participation in fascist politics in France, Germany, Italy, and the UK (Durham, 1998).Women "shockingly" participating in far-right politics has received much media attention despite fascist movements being known for stressing women's responsibilities at home. Conservative ideals of good fascist mothers and wives have also been prominent in CPI's propaganda (Provost \& Whyte, 2018). According to Gretel Cammelli, "since the foundation of CasaPound, women's presence was overexposed, but in reality, there was a small number of them." Cammelli observed that back in 2010, in CPI "women's roles were extremely marginal, they were basically absent from all the high hierarchies," and that the movement is very "macho." The researcher recalls that she went to a CPI event in 2010 and "the number of women was quite embarrassing: they were about 20 out of 500 people. Almost all of them were in the kitchen, preparing sandwiches for the men" (Torrisi, 2018).

All of this makes the movement edgy and decidedly masculine-87 percent of the CPI's Facebook supporters are male (Jones, 2018; Bartlett et al., 2012). According to the CPI's ideology, today as in the fascist era, the role of women is to procreate for the wealth and prosperity of the Italian nation. Women have a duty to ensure that the history of Italy is kept alive into the future, and CasaPound perpetuates a normative vision of female gendered identity (Gretel Cammelli, 2018). Caterina Froio notes that the far right has struggled with the so-called "gender gap" among members, voters, and political personnel because women represent a large potential reservoir of support electorally for the far right (Torrisi, 2018).

In 2017, CasaPound expressed support for same-sex marriage and supported abortion rights. Even if it is not officially homophobic, CasaPound believes in the "traditional family" as the basic unit of the nation. One example of this was the "Tempo di essere madri" "It's time to be mothers") campaign, which advocated lowering the amount of working hours for mothers without affecting their pay (Bartlett et al., 2012).

In November 2017, the Italian edition of the women's magazine Marie Claire published an article entitled "Do you know who CasaPound's women are?" It profiled female militants of CPI, giving readers a glimpse into their private lives, sharing fashion tips, what they like to wear, and how they juggle their family and social lives with the demands of being part of a violently fascist movement (Torrisi, 
2018). Like Marie Claire, the Italian media in general have helped CasaPound to "glamourise" fascism. Torrisi shows how media coverage focused on the movement's female members has fawned over their beauty and their dedication to their children and husbands, while glossing over the violence and danger of this increasingly visible fascist group (Provost \& Whyte, 2018). For instance, Italian media christened local spokeswoman Carlotta Chiaraluce in Ostia "Lady CasaPound" and called her a "beautiful, fascist... vote-catcher" and the "queen of the far-right movement." Interviewed by one right-wing newspaper, Chiaraluce said that there are a lot of women in the movement, and they are all happy with what they are doing. She said: "Even if there is not a lot of media attention on this aspect, we are deconstructing the theory of the misogyny of fascists" (Torrisi, 2018).

\section{Hybrid Ideology Facilitates Diversified Activities}

CPI emphasises direct activism, and its strategy is based on the synergic union of ideas and actions. In CPI's view, ideas cannot be separated from political participation (Bulli, 2019) and it has successfully managed to construct its own self-styled activism (Castelli Gattinara \& Froio, 2015). Thus, CPI enjoys important visibility in Italy and in the European extreme-right subcultural milieu despite its limited number of supporters (Bartlett et al., 2012).

Until the late 2000s, CasaPound was mainly engaged in expressive activities aimed at developing its network of associations. It was also protagonist of a series of demonstrations, which included the occupation of a state-owned building in Rome in 2002 (CasaMontag) and developing a number of "non-conventional" squats, the attack against the emission "Big Brother," and numerous violent riots involving Blocco Stundentesco (Castelli Gattinara \& Froio, 2015).

Meanwhile, CPI's political campaigns have aimed to implement laws, promote referenda, and directly influence the national political debate over different topics related to housing, Italian workers, the public austerity programme, and the importance of the traditional family (Bartlett et al., 2012). In its early years, it stood out for its unconventional actions, most notably highly demonstrative protests, occupations of state-owned buildings for housing purposes, and squatting for political and cultural activities. Even during electoral campaigns, CPI combined conventional party activities such as handing out leaflets, collecting signatures, and promoting fundraising events with contentious politics, including the storming of rival candidates' offices, clashes with anti-racist and anti-fascist organizations, and direct actions and interventions (Pirrò \& Castelli Gattinara, 2018).

As mentioned previously, CPI builds its political narrative upon the framework of the "metapolitics": a counter-cultural power for which cultural change is expected to precede political change. This is also confirmed by the groups' preferred modes of activism; it engages in a number of different arenas (Castelli Gattinara \& Froio, 2015). The hybrid nature of CPI has shaped its actions, which consists of both unconventional and conventional activities (Bulli, 2019).

From its very beginnings, CPI insisted on the creation of an image that diverged from the institutional character of the Italian far right of the late 1990s (Bulli, 2019). It has adapted a "new political style." Instead of parades, memorial rituals, or celebrations, they organize rock concerts where people can meet up and "community" can form and, through chorus and dance, celebrate itself. Music has especially played a crucial role in this strategy. Producing music and live performances has been seen as one of the principal ways of creating the desired distinction between the traditional far right and the new model proposed by CPI (Bulli, 2019).

This is possible thanks to CPI's leader Gianluca lannone, who is also the front man of the rock band ZetaZeroAlfa (ZZA), which lies at the origins of the entire movement. Iannone is an actor capable of updating the new political style, making the CasaPound community feel a desire 


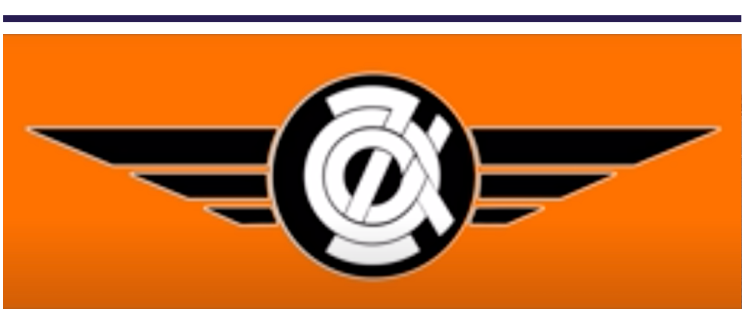

The emblem of ZetaZeroAlfa (ZZA).

to take part in the leader's power. When lannone sings and stands at the centre of the stage, everyone flocks to be near him. As one activist stated, ZZA is not a single artist; rather, "if you listen to Zeta Zero Alfa, you understand that they are like the tip of the iceberg, that there is a whole community behind them." ZZA's concerts are an important tool for communication. One of ZZA's most well-known songs is called "Cinghiamattanza." When "Cinghiamattanza" is performed, the activists take off their belts and begin to beat each other with them, often until bleeding, as the lyrics themselves encourage them to do (Gretel Cammelli, 2018). CasaPound defines "cinghiamattanza" or "massacre belt" as a "sport" (Lidell, 2012).

Another distinguishing feature of CasaPound is its explicit emphasis on physical activity and confrontation. The function and importance of sports and physical confrontation is more broadly conceived as a "cult of the body." CasaPound offers a range of sporting activities to its core members and sympathisers, including trekking, speleology, rugby, combat sports and martial arts, karate, boxing, wrestling, parachuting, water polo, diving, horse-riding, motor-riding, and hockey (Kington, 2011a). These activities allow those who practise them to show courage and masculinity. CPI is also engaged with a number of youth clubs dedicated to sports, as well as with art galleries and theatre schools. Similarly, sports and leisure activities play a fundamental role in developing a sense of shared community (Bulli, 2019; Wolff, 2019).

Since camaraderie is represented as the highest form of political and social commitment for its members, CPI adopts a particular style of communication intended to present the group as a valid alternative to the traditional politics (Bulli, 2019). Thus, CPI organizes solidarity actions so as to reinforce its close connection to the social legislation of the Fascist regime. CPI's grassroots associations play a crucial role in these activities, in which there is direct contact with those being helped and CPI promotes a series of "para-welfare activities" addressed to Italian families facing difficult times (Castelli Gattinara et al., 2013). Unlike conventional forms of activism, they do not seek the mediation of representative authorities to solve public problems, but seek to directly redress a problem (Bosi \& Zamponi, 2015: 371). These actions were at the core of campaigns on housing rights and extended to other issues over time. CPI then mobilized on environmental requalification and voluntary work to help disabled, unemployed, and elderly people (Pirrò \& Castelli Gattinara, 2018). CPI's engagement in society covers a wide range of different activities, from house-occupation and street protest to social welfare and housing programmes, from vigilante excursions against illegal migrants in the peripheries of Italian cities or against illegal street sellers on Italian beaches to pro-bono health and legal counselling, first aid teams, fundraising activities for foreign populations, and aid to orphans and single-mothers (Wolff, 2019).

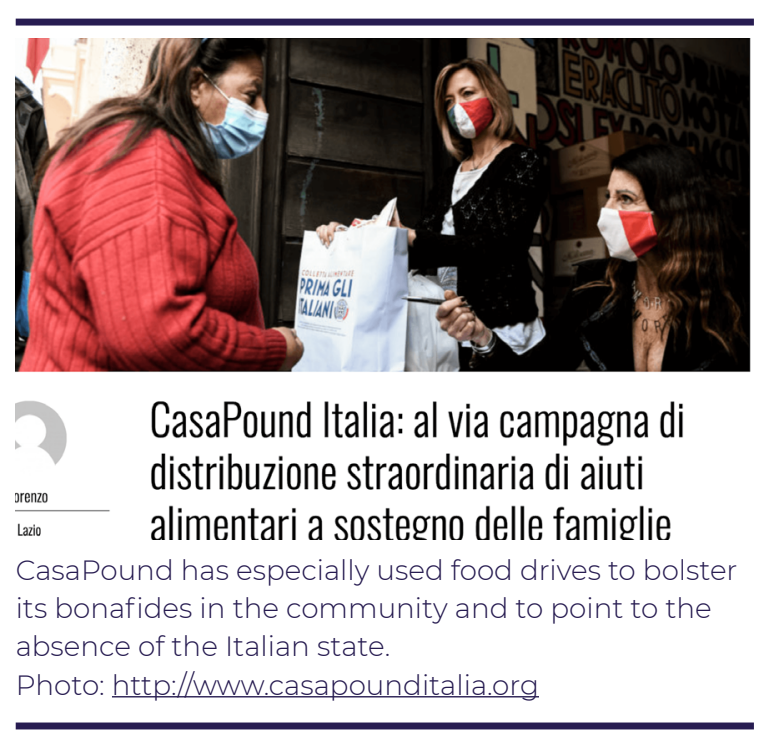

CasaPound has especially used food drives to bolster its bonafides in the community and to point to the absence of the Italian state "that should take care of its own before it takes care of others." Through such actions, CasaPound spectacularizes Italy's social precarity, while 
less-than-obliquely hinting at a logic of crisis induced by the non-Italian "other" (Bialasiewicz \& Stallone, 2020). CPI has especially worked for the working class and peasantry and set up its own workers' union. In 2006, CPI members hung 400 mannequins all over Rome protesting the city's housing crisis; and in 2012, they occupied the EU's office in Rome and dumped sacks of coal outside to protest on behalf of Italian miners (Jones, 2018).

As mentioned above, CasaPound combines traditional right- and left-wing concerns, approaches, and symbols. For example, despite an open devotion to Mussolini, it regularly organises events to celebrate famous left-wingers such as Che Guevara or Peppino Impastato (a militant communist who died fighting against the mafia in Sicily). These ambiguities are also reflected in the group's culture and music: its official radio station, Radio Bandiera Nera, broadcasts traditional right-wing music as well as the anarchist songs of Fabrizio De Andrè. The images used by the group include the so-called fascio littorio (the symbol of Mussolini's ideology and regime), as well as posters of Corto Maltese or the leftist singer Rino Gaetano. These ambiguities account for CasaPound's appeal, particularly among young people, as they strive to appear as non-conformist as possible. The anti-conformism is a strong pillar in the language of the organisation(Bartlett et al., 2012).

According to Castelli Gattinara, CasaPound aims at constructing a sense of comradeship by diversifying its political supply across numerous issues, inspired by a philosophy of life built on fascist myths and aesthetics, and on a mix neo-romanticism, irrationalism, spiritualism, and volunteerism. It is in this framework that CasaPound has developed its environmental project La Foresta che avanza (The forest that advances), which takes inspiration from the fascist's "Mystic of the Earth." CasaPound's volunteerism is also mirrored by its social and civic engagement (such as La Salamandra, which operates in territories tormented by natural and/or humanitarian disasters) (Castelli Gattinara et al., 2013).

lannone has stressed the logic behind the CPI's activism and said that Casa-
Pound works on dozens of projects and with various methods: "It is fundamental to create a web of supporters rather than focusing on elections. For elections, you are in competition with heavily financed groups and with only one or two persons elected, you can't change anything. Politics for us is a community. That is why we are in the streets, on computers, in bookshops, in schools, in universities, in gyms, at the top of mountains or at the news stands. That is why we are in culture, social work, and sport" (Liddell, 2012). More than four in ten ( 44 percent) of CPI's Facebook supporters reported participating in a street demonstration or protest. However, only one in five reported being a formal member of CasaPound. This might reflect the wider appeal that CasaPound cultural activities hold for people (Bartlett et al., 2012).

\section{Violence as a Method of Demonstration and Expressive Action}

The main traits of Italian Fascism and the mythology of violence are inseparable (Lupo, 2005). The widespread use of violence and violent vocabulary by CPI has also to be understood as an explicit reference to Italian Fascism, which was strongly characterized by a martial rhetoric and by the glorification of violence (Blinkhorn, 2000: 69). In Mussolini's system of values, violence represented the most just and moral, as well as the most practical way to defend one's ideas. In a similar way, CasaPound's militants glorify their political activism in terms of battlefield values and concepts (Castelli Gattinara \& Froio, 2014). Violence is actually a basis for the "militia" identity (Payne, 1999). Research (Bjorgo \& Witte, 1993; Bjorgo, 1995) has shown that militants, supporters, and sympathizers are incentivized to violent action by the organization, which offers rationales for mobilization and synthesizes grievances in political and ideological discourses based on race, religion, and gender superiority. Similarly, justifications may be based on symbolized concepts such as the homeland, blood, and honour (O'Boyle, 2002; Taggart, 2000). 
Despite acts of violence being rejected in official CPI policy, the group declares itself ready to defend itself in case of challenges to its survival (Bulli, 2019). CasaPound's most explicit position with respect to violence can be found on its official website's FAQ section: "CasaPound Italia does politics, not hooliganism. CasaPound is not interested in showing its muscles. CasaPound calls for quiet force. At the same time, however, CasaPound does not allow others to challenge its legitimate right to exist and act. We are open to dialogue, but we don't reject confrontation when this is imposed on us and when our political and physical survival is at stake." CasaPound militants also claim that they're constantly under attack from anti-fascists. "We're not a violent organisation," one militant said, "but we're not non-violent either." CasaPound has sometimes relished its violent reputation, and has sometimes been angered by it (Jones, 2018). Violence is not officially endorsed, yet neither is it fully rejected; it remains an important corollary to political activism (Castelli Gattinara \& Froio, 2014).

CasaPound's position on violence, therefore, has to come to terms with two opposing forces: i) The necessity of protecting the movement's external credibility, which would require a full rejection of violence; and ii) The ideas and rhetoric of Italian Fascism were built upon a number of inherently violent elements, such as the cult of bravery and squadrismo. Squadrism expresses the image and memory of fascist violence, a specific kind of political violence committed in particular against political opponents with the purpose of gaining power (Gretel Cammelli, 2018). Since Italian Fascism justified the use of violence against its opponents on the basis of the alleged superiority of its political ethics (Gentile, 1934) and also as a tool to safeguard the group's right to expression against coercion and repression, it is impossible for CasaPound to completely disregard violence (Castelli Gattinara \& Froio, 2014). In this sense, violence represents the noblest form of resistance against a hostile, repressive external world and becomes a means not only of survival but also of self-determination (Scianca 2011: 362).

CasaPound cadres often underline how physical training is fundamental for CasaPound militants, as they should always be ready and "physically trained for any threat." Castelli Gattinara \& Froio (2014: 158) note that there is a threefold function of violence within CasaPound's identity, discourse, and practices. In the first place, violence should be understood in terms of a discursive dimension (Koopmans \& Olzak, 2004). It rejects political violence as a means to achieve policy success in its external rhetoric. Yet, given its need to reconnect with its fascist past, violence cannot be fully erased from the CPI's political platform. The result is the development of a specific narrative in which violence is framed as a defensive tool used to respond to forms of repression. Secondly, violence emerges within an aesthetic dimension, by which CasaPound romanticizes and reproduces the myth and symbolic violence of Fascist Italy. Lastly, violence plays a fundamental role in CasaPound within an identity-building dimension (Castelli Gattinara \& Froio, 2014).

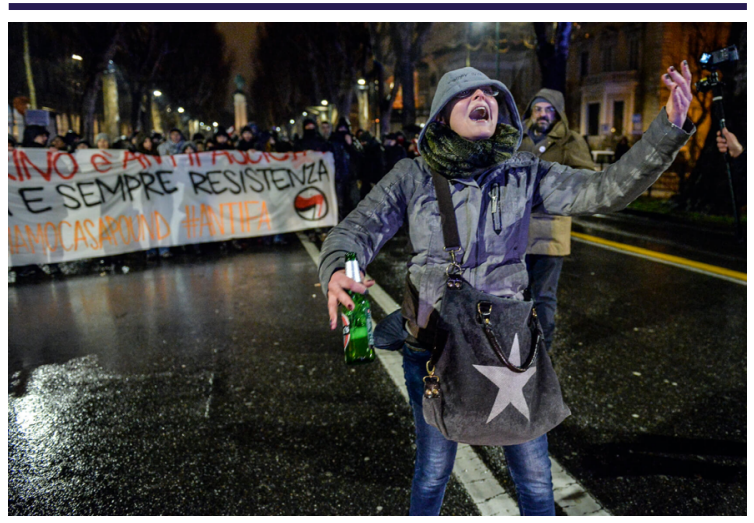

Anti-fascist protest against the candidate of the fascist political party Casapound. Clashes between antagonists and police in Turin, Italy on February 22, 2018. Photo: Stefano Guidi.

The use of violence has been mythologized in CPl's images and practices. A good example is cinghiamattanza (belt-fighting) in which violence is directed not against out-groups but within the in-group (Castriota \& Feldman, 2014: 231-232). The practices of physical violence are used to build feelings of comradeship. The medium through which networks of solidarity are built within the community is the (male) body, through practices of physical contact where the body of the militant is symbolically blended with the collective body of the community. The 
most widespread of these practices is collective training in combat sports. Common participation in combat sports is a fundamental moment where the militant joins in spirit and body with the collective entity.

Besides its instrumental use as a form of action, violence also plays a fundamental role in the group's narrative and political discourse. Violence, in other words, is rationalized as a form of resistance against an oppressive and "intolerant" anti-fascist society. Yet, when approaching internal audiences, violence emerges as a fundamental tool to strengthen solidarity and camaraderie among group members (Castelli Gattinara \& Froio, 2015) and plays a role as a constitutive element of the group's collective identity and collective socialization (Castelli Gattinara \& Froio, 2014).

In the public domain, CasaPound shifts the attention away from its own use of political violence, focusing instead on repression it suffers. This strategy allows the group to avoid the stigmatization often suffered by extreme right organizations (Castelli Gattinara \& Froio, 2014). Authors increasingly recognize the importance of collective narratives, rituals, and symbolic repertoires in the development of protest events and violence and within processes of exclusive identity building (della Porta, 2013; Goodwin, 2004). In this understanding, the symbolic, cultural, and emotional aspects of political violence are often more significant than its material and strategic consequences. Recent research has in fact rediscovered the role of emotions in the construction and structuring of collective identities (Aminzade \& McAdam 2001; Goodwin et al., 2001). Apart from physical violence, CPI makes strategic use of the mythology around a readiness to fight, verbal and physical confrontation, and speed of response in case of attack (Bulli, 2019).

As Castelli Gattinara and Froio (2014) have suggested, violence in CasaPound is linked to the history and rhetoric of fascism "justifying the use of any kind of violence against its opponents." Violent activities have accompanied CasaPound since its birth. Reports on CasaPound in the newspaper La Repubblica between
2004 and 2012 show that about 15 percent of reported CasaPound actions were confrontational, while an additional 35 percent of events involved some form of violence (Castelli Gattinara \& Froio, 2014). Moreover, about a third of press releases issued by $\mathrm{CPI}$ involve physical or symbolic violence (Pirrò \& Castelli Gattinara, 2018). Another analysis of CasaPound's activism between 1995 and 2013 reveals that 51.5 percent of activities have been confrontational and violent (Castelli Gattinara \& Froio, 2015).

Music is another fundamental element for understanding CasaPound's semiotic of violence (Eyerman \& Jamison, 1991). Although extreme right musical culture has generally been associated with the skinhead scene, similar tendencies have recently permeated other subcultures (O'Connell \& Castelo-Branco, 2010). In the music of ZZA, violence is associated with a set of different meanings. First of all, it represents a revolutionary tool to fight the habits of consumerism and cultural homologation, and to oppose the rulers of the country and the economic system (Castelli Gattinara \& Froio, 2014).

On December 13, 2011, Gianluca Casseri, a CasaPound sympathiser in Tuscany, left home with a Magnum 357 in his bag. On that morning, 50-year-old Casseri had a plan to shoot as many immigrants as possible. He went to a square in Florence and, at 12:30 pm, killed two Senegalese men. He shot another man in the back and throat and then got in his car and drove off. Just over two hours later, Casseri was at the city's central market, where he shot two more men, who survived the attack. He then turned his gun on himself in the market's underground carpark (Jones, 2018). These murders suggest that a mythological narration of the past does not prevent it from being reproduced in the present (Gretel Cammelli, 2018). 


\section{Neo-Fascism as Show Business}

The relationship between extreme rightwing organizations and the media is far from straightforward. The far right is, on the one hand, traditionally suspicious of the media which it blames for promoting liberal values and sustaining the status quo (Mudde, 2007); media attention, on the other hand, allows dissemination of far-right messages (Ellinas, 2010). In such a context, Castelli Gattinara \& Froio (2015) underline that newsworthiness is the primary motivation for CPI's choice of showcase activism and the group is primarily involved in the organization of highly media-friendly events and actions, specifically by tackling ongoing problems and public concerns, using new vocabularies, innovative symbols, and unconventional forms of protest.

$\mathrm{CPI}$ has also been well aware that their visibility depends on the capacity to offer the media a product that is at the same time personalized, spectacularized, and creating controversy and debate (Esser, 2013). The media interest in CPI can, thus, be explained by their fascination with the imaginary of violence, marked by the group's simultaneous use of conventional and unconventional forms of activism mostly centred on its idealization of a myth of action, courage, and predominantly masculine bravery (Bulli, 2019). Images traditionally associated with Italian Fascism, such as warriors, soldiers, etc., are also part of CasaPound's visual communication (Mosse, 1996) which aims at increasing the visibility of CasaPound in the media-which may represent a fundamental tool for CPI's survival (Castelli Gattinara \& Froio, 2015).

What makes CasaPound unique is its game of smoke-and-mirrors with fascinated Italian media. The media-whether intrigued, anxious, or excited-has reported on every initiative: as Di Stefano said, "everything CasaPound did became news" (Jones, 2018). There is a convergence between CPI's activism and its communicative strategies. In this sense, the framing, and actions of CasaPound are first based on an accurate study of the mechanisms of news production and subsequently justified ideologically. In so doing, CasaPound is more than simply recognizable; it is a "trademark" that can be identified well beyond the traditional audiences of neo-fascism. Today, vast shares of Italian public opinion are very familiar with CasaPound thanks to CPI's performances and ability to attract media attention (Castelli Gattinara \& Froio, 2015).

Moreover, CPI pays particular attention to the promotion of its events on its online platforms, so that journalists often find all the information, photos, and material they need directly from the sources of the relevant group, thus allowing CPI to exert control over its own imagery and narratives. Accordingly, demonstrations and public events are organized and planned with extreme caution to produce "iconographic" results. CPI has thus demonstrated a considerable knowledge of developing a form of storytelling based on dramatization of narratives, visual staging of protest, and the construction of controversy by means of symbolic innovation and discursive hybridization (Castelli Gattinara \& Bouron, 2020).

Thank to hybridization strategies-i.e. the strategic combination of organizational features and activities inspired by different political cultures, institutional party politics, and non-institutional contentious actions-five features of CPI's politics are blurred: ideology, internal structure, activism, mobilization, and communication. Hybridization in these five main aspects of extreme right politics allows CPI to attract quality media attention while also validating extremist views in the public sphere (Castelli Gattinara \& Froio, 2020) via agitprop (agitation propaganda) actionspropaganda and demonstrations aimed at mobilizing public support. CPI benefits from this strategy of hybridization, which taps into commercial media demand for entertaining stories and simplified messages. Its unconventional mix of extreme right, pop-culture, and left-progressive styles helps ensure media coverage in both the protest and electoral arenas (Castelli Gattinara \& Froio, 2019).

In terms of political symbols, CPI also offers a hybrid media product associating pop and left-wing icons with extreme 
right codes. The goal is not only to empty established symbols of their meaning, but also to present an innovative and unusual narrative for responding to the commercial needs of the mass media (Castelli Gattinara, 2017). Through hybridization and media-savviness, CasaPound increasingly meet the commercial media appetite for sensational, entertaining stories and polarizing news. Ultimately, CPI has realized that complying with the logistics of news production helps ensure that fringe or extreme ideas drift into the mainstream (Castelli Gattinara \& Froio, 2019).

CasaPound have reconstructed fascism as what Castelli Gattinara and Froio have characterized as a "hybrid communication style." Images of Mussolini and fascist iconography mingle with references to cultural figures sympathetic to fascist ideas, or those who might be termed proto-fascist-Ezra Pound, obviously, but also Marinetti, D'Annunzio, Sorel, Knut Hamsun, Yeats, and Nietzsche. The effect is a strange collage of nostalgic nods to the years of the fascist ventennio and to "pop culture" (Barnes, 2019). CPI's visual propaganda also features Che Guevara and Karl Marx alongside popular pirate cartoon characters Corto Maltese and Captain Harlock, and music by anarchist songwriter Fabrizio De André (Castelli Gattinara \& Froio, 2019). This strategy has gained CasaPound a significant degree of media attention. News agencies seem to be interested in the phenomenon of "acquisition" of left-wing issues and repertoires of action by extreme-right organizations: CasaPound's squats, concerts, and "showpiece" protests, as well as the attention it gives to issues such as homosexual rights and the environment (Castelli Gattinara et al, 2013).

Moreover, CPI activists favour hip symbols and neutral clothing-jeans and T-shirts-rather than stereotyped extreme-right styles, such as shaved heads and combat boots. This improbable mix of aesthetic influences has fascinated the Italian media, building the notion that CPI promotes a new, glamorous approach to extreme-right politics (Castelli Gattinara \& Froio, 2019). Meanwhile, to maximize the visual impact of CPI's demonstrations, participants form ranks of seven or eight persons and then march in orderly lines separated from one another by a maximum of two meters. Ideologically, these practices clearly reflect the idea of order and unity-strategically, they help the group to exert control over its own image when it interacts with the mass media during public events and enable it to extend its visibility well beyond the extreme-right milieu (Castelli Gattinara \& Bouron, 2020).

Competing in elections also increased CPI's presence in the mainstream media. To enhance its political newsworthiness, CPI developed professionalized media management techniques designed to locate the party on the "friend" side of the "friend-foe" relationship between the media and the radical right. To do this, CPI specifically satiated the media's desire for the spectacular and theatricality (Bulli, 2019). CPI made use of theatricality in all its political demonstrations, from traditional rallies to symbolic performances. By employing shocking tactics-like hanging dummies from town bridges in order to denounce rising prices, unemployment, and the pressures of immigration, or dyeing the water in the Senigallia fountain red in memory of the blood of Italians who committed suicide due to the pressures of debt-the movement achieved extensive media coverage. CPI used the term "squadrismo mediatico" (media squadrism) to describe this strategy (Bulli, 2019).

Gretel Cammelli (2018) lists some of CPI's actions that have been defined as "mediatic squadrism": a 2012 demonstration inside a high school in Rome that involved setting off smoke bombs and shouting for the Duce (Mussolini) to return; an incursion into the public television studio (Rai Tre) in 2009 to express disapproval of a programme (Chi l'ha visto), in which militants ran into the studio and warned the Italian public and politicians "not to play with their lives." They had several t-shirts printed bearing the text "perfect squadrist style: dress up as a rockstar." The media helps CPI gain visibility by providing attention to issues on which they enjoy enhanced public credibility, notably immigration and security (Boomgaarden \& Vliegenthart, 2007).

When CPI has sought to clean up its 
image in order to penetrate mainstream Italian political debate, the media have again played a starring role in the project, helping to normalise and even glamourise the far-right movement (Torrisi, 2018).

While CPI's outward-oriented media practices have shaped public policy and state action, and/or set the terms of public debates and agendas, it also displays an internal media politics focused primarily on reinforcing ideological consistency and subcultural identification and constructing a brand identity that ensures internal cohesion and external distinctiveness. Hence, inward-oriented activism stands out for its function in structuring collective identities and ideological coherence (Castelli Gattinara \& Bouron, 2020) associated with an alternative culture and community (Atkinson \& Berg, 2016). Rather than being solely an instrument of internal propaganda and control, inward-oriented media practices serve the purpose of building the collective identity of the groups, binding militants within a common culture and ensuring their coherent representation towards the outside world (Castelli Gattinara \& Bouron, 2020).

$\mathrm{CPI}$ is also expert in the use of social media. It uses social media to garner support and help appeal to a young demographic. The language they use tends to be based on slogans, incitements, and abstract concepts, rather than articulated ideological positions.

In addition, they use self-produced media innovatively (Bartlett et al., 2012). It now counts on one Internet television channel (Tortuga TV) and a monthly newspaper (Occidentale). The radio channel Radio Bandiera Nera (RBN, Black Flag Radio) was created in 2007. Initially hosted on the online forum Vivamafarka, RBN is now carried on fifteen radio stations in Italy and three abroad. It puts out political and cultural news and interviews, but its main content is far-right music. In 2013, the newspaper II Primato Nazionale was created as an online newspaper covering CPI's internal and external activities. Since its founding, it has become the press organ of $\mathrm{CPI}$ and hosts articles by its most prominent political and cultural figures (Bulli, 2019).
Indeed, there is a considerable symmetry between CPI's internal structure and its media apparatus. The group can count not only on official social media profiles (Facebook, 240,000 likes; Twitter, 18,000 followers), and on a website summarizing its basic values, activities and proposals, but also on dedicated pages for each territorial branch, and individual pages for national leaders and candidates.

Despite this fragmentation, these online platforms are very coherent in aesthetic choices and in the diffusion of messages. The graphic design and format of all websites and platforms are intended to provide a sense of ideological purity and belonging, not only through the selection of symbols, but also through the homogeneity of colours and fonts, creating a continuity between the main portal and the pages of its peripheral organizations and increasing the distinctiveness of the network. At the same time, these choices closely correspond to those observed in CPI's offline communication and activities (Castelli Gattinara \& Bouron, 2020).

The coherence of CPI's network is ensured by online activists and "web-supporters." Web supporters are "CPI's online task force" and are as important as other members and activists. In this respect, CPI's media practices also produce innovative and more flexible forms of participation beyond traditional party membership (Castelli Gattinara \& Bouron, 2020). However, Facebook and Instagram closed CPI's official accounts in 2019. A Facebook spokesman told the Italian news agency Ansa: "Persons or organisations that spread hatred or attack others on the basis of who they are will not have a place on Facebook and Instagram" (Tondo, 2019). However, a civil court in Rome has ruled that Facebook must immediately reactivate CPI's account and pay the group $€ 800$ for each day the account has been closed (Giuffrida, 2019; Global Freedom of Expression, 2020). 

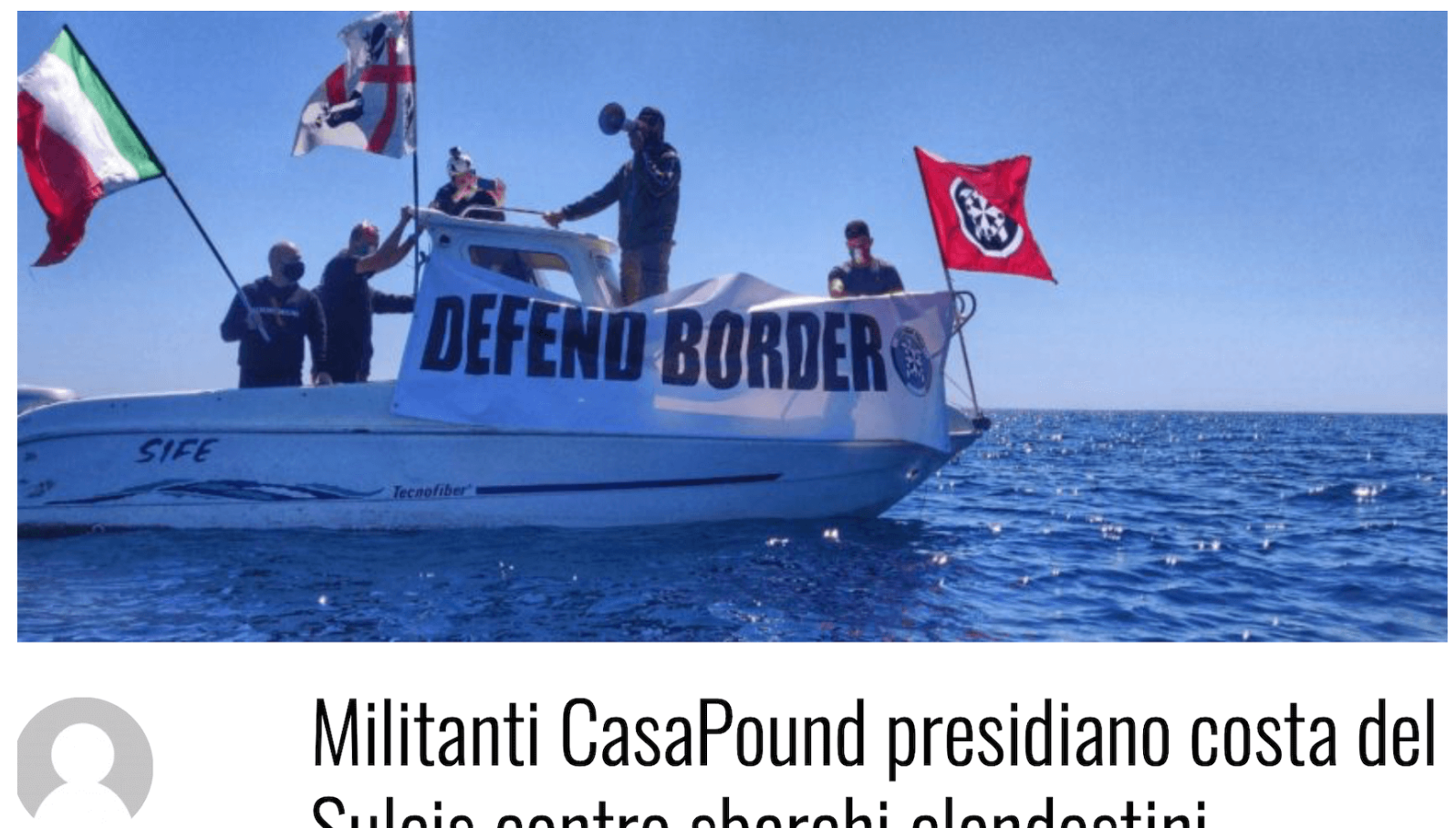

\section{Militanti CasaPound presidiano costa del Sulcis contro sbarchi clandestini}

lorenzo

\section{Anti-Immigration $\&$ Antisemitism}

While CPI supporters oppose immigration and multiculturalism, their arguments against immigration are unconventional and on "progressive" grounds (Jones, 2018) compared with other farright-wing organisations and is an example of "care racism." CPI argues that immigration is bad for the immigrants themselves, as it is a form of "modern slavery" (Bartlett et al., 2012).

"We want to stop immigration," says Di Stefano. "Low-cost immigrant workers mean Italians are unable to negotiate wages, while the immigrants are exploited" (Kington, 2011a). Though Italy has fewer migrants than many other Western European countries (Eurostat, 2019), conservative lawmakers have painted an alarming picture of an invasion that has plunged the country into an unmanageable emergency (Povoledo, 2018). According to Bartlett et al. (2012), CasaPound's arguments against immigration are mainly economic in nature. CasaPound argues that it is not against immigrants per se, but rather criticise immigration as a forced result of globalisation. They claim that globalisation creates a "multirazzista" (multiracist) society, where the rising number of immigrants prevents the state from protecting its own citizens.

In the political programme of CasaPound, migration constitutes the third priority, and the movement states its clear opposition to the "migration mechanism." The programme proposes "blocking all migration inflows, sending back all irregular migrants, and sustaining any identity-based movement active in other countries capable of promoting the re-settlement of people in their own countries." CasaPound declares its desire for "a world where the differences are protected and promoted... in order to prevent the confusion and spoiling of each identity." Succinctly, it is stated in the programme: "Stop invasion; Italians first!" (Gretel Cammelli, 2018). The "real human values" are expressed through a racially exclusionary, moralized claim on social housing. Leading up to the 2018 elections, the movement recalibrated their discursive and material focus on the housing issue in more directly xenophobic terms, with the slogan "Italians should come first 
and then, maybe, foreigners" (Bialasiewicz \& Stallone, 2020).

The "manifesto della razza" published in Italy in 1938 affirmed the existence of hierarchically positioned races and the importance of preserving the "Italian race" before all others. CPI has edited its programme to eliminate any explicit references to the racist policies of the fascist epoch; nevertheless, many CasaPound statements reveal an updated version of this tendency to consider human beings different from one another (Castelli Gattinara, Froio \& Albanese, 2013: 250). These statements provide an example of what in the social sciences is known as "differential racism" (Wieviorka, 1998).CasaPound does not grant any value to race as a genetic attribute, but identity is promoted as a feature deriving from the person's culture and linked to a specific national territory. In this discourse, such identities are naturally linked to national borders and history, elements which determine the specific culture of the area in question. This specific culture in turn produces the identity of individuals, and CasaPound has declared itself ready to defend these specific cultures and traditions against the supposed risk of contamination entailed in encountering and living with different cultures. According to this logic, migrants should be sent back to their own countries because different cultures cannot live together. This example of cultural fundamentalism (Stolcke, 1995) claims different access to citizenship and civil rights depending on the origins of the individual in question (Gretel Cammelli, 2018).

CasaPound's actions often target centres hosting migrants and asylum seekers through outright attacks (Selmini, 2016) or symbolic demonstrations. Throughout 2014 and 2015, CasaPound's leaders organised rallies against asylum centres that were due to open. All over Italy, every time a vacant building was converted into an asylum centre, CasaPound members contacted local citizens opposing the centres, offering strategic advice (Jones, 2018). This occurred, for instance, in Goro Gorino in the autumn of 2016, when CasaPound and Lega Nord activists coordinated with local resident to put together a committee to prevent asylum seekers from settling in the town, erecting a barricade across the street at night. CPI members also invaded the emergency area of a hospital in Bolzano in 2018 to protest homeless people who took refuge there overnight (Povoledo, 2018).

Furthermore, in May 2019, angry protesters and members of the CPI tried to block a Roma family from accessing its assigned council apartment in the Casal Bruciato district of Rome. When riot police escorted a woman and her child back to the apartment, some protesters raised their arms in a fascist salute; others shouted racial insults and rape threats (Castelli Gattinara \& Froio, 2019). Some female residents in the district said, "we want to see them all hanged, burned." "Shall we call Mussolini back from the dead?" asked another woman ironically. "I wish," replied the others (ANSA, 2019).

Eventually, CasaPound militants went on to actually kill migrants. The first incident took place in Florence in 2011, when a CasaPound militant with a gun shot and killed two workers from Senegal; another occurred in Fermo in the summer of 2016, when a CasaPound sympathizer beat an asylum seeker to death. CasaPound's rhetoric of opposition to migrants and different cultures open the way for violent actions and shows how the fascist past can find space for its mythological narration and thereby legitimize a specific identity in the present (Gretel Cammelli, 2018).

Meanwhile, despite CPI's Di Stefano stating that Mussolini's racial laws were "a mistake... We believe in the national community and the Jews in Italy are part of that," (Kington, 2011a) CPI is antisemitic. It cooperated with Lebanese radical Islamist group Hezbollah in 2015. While CasaPound borrows a significant amount of its ideology from Italian Fascism, it attempts to disassociate itself officially from antisemitism (Staff, 2012).

CasaPound has condemned Mussolini's racial laws as a mistake-while also adding that they have to be understood in a context in which antisemitism was a worldwide phenomenon and not specifical to Italy (Castelli Gattinara \& Froio, 2015). Di Stefano said, "We are not racists, we are not antisemitic, we do not have problems with Israel," when CPI's political ally 
Matteo Salvini was denied entry into Israel on the purported basis of his CasaPound connection. In 2018, Di Stefano defended then-Israeli Prime Minister Benjamin Netanyahu's policies regarding repatriation of illegal immigrants to Africa as "undoubtedly excellent," and criticised humanitarian organisations and the United Nations for intervening to prevent them.

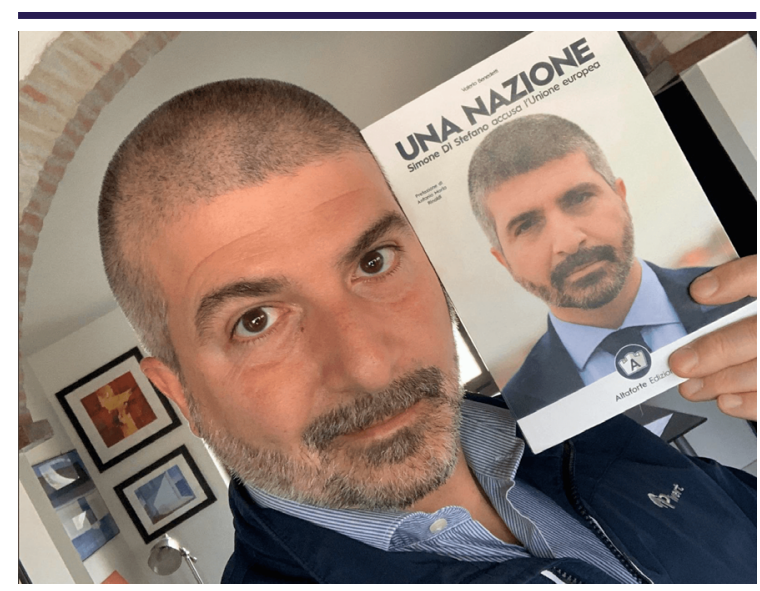

Simone Di Stefano. Photo: @distefanoTW

\section{CasaPound's}

\section{Transnational}

\section{Connections and} Impact

Despite being a small group, CPI has been able to set an example for extreme-right social movements (Koch, 2013).Indeed, CasaPound has become a reference point at the European level, attracting the attention not only of the observers of political extremism, but also of the media and the public (Castelli Gattinara \& Froio, 2015). Over the years, CPI's leaders have been invited to explain its "political model" in many major European capitals (Paris, Madrid, London, Lisbon, Brussels, Warsaw). In 2011, the Finnish Resistance Movement invited members of CasaPound to a seminar in Helsinki (YLE, 2011). Other extreme-right organizations in Europe are also increasingly studying CasaPound's experience: in November 2014, the leader of CPI was invited to the international conference, "The Awakening of Nations," organized by the French
Groupe Union Défense, along with other extremist groups such as the Greek Golden Dawn (and its Cypriote branch ELAM), the Belgian Nation, the Spanish Movimiento Sociale Republicano and Liga Joven, the French Mouvement d'Action Sociale, and some representatives from the online platform Synthèse Nationale (Castelli Gattinara \& Froio, 2015).

Moreover, CasaPound has always voraciously consumed foreign trends and repackaged them for an Italian audience: it absorbed the anti-capitalist ideas of France's Nouvelle Droite movement and built friendships with members of Greece's neo-Nazi Golden Dawn (Jones, 2018). CasaPound has also promoted initiatives outside Italy through its non-profit organization Solidarité Identités. Through the Sol.Id network, CasaPound activists have engaged in projects in Burma, Crimea, Kosovo, Palestine, and Syria. Ten percent of CasaPound's income is dedicated to the efforts of Sol.Id. Despite the group's engagement in Syria, in support of the Assad government's "struggle to defend its people" CasaPound activists saw no contradiction between supporting the Syrian people in their homeland and being opposed to granting asylum to Syrians fleeing to Europe (Bialasiewicz \& Stallone, 2020).

On foreign policy, CPI's core beliefs include fondness for Russia and sharp opposition to the EU, globalization, and immigration (Horowitz, 2017), and supporting a communitarian-nationalist Europe. CasaPound Facebook supporters have very negative attitudes towards the EU. CasaPound supporters were significantly more likely to cite the following when asked about their views about the EU: loss of cultural and national identity (63 percent vs only 12 percent of the Italian general public); waste of money (48 percent vs 16 percent); bureaucracy (33 percent vs 7 percent); and not enough control at external borders (46 percent vs 9 percent) (Bartlett et al., 2012). Nevertheless, CPI defines itself as a pro-European organization, unlike many contemporary radical-right movements. Once more, this element connects them to the tradition of the neo-fascist right dating back to the early 1950s, when fascist groups were transnational actors proposing an ideal European nation-state 
based on shared traditions and homogeneous cultures and values. To these ideals, CasaPound adds the proposal of a protectionist Europe, with the goal of achieving a European-wide area of economic and welfare self-sufficiency (Castelli Gattinara et al., 2013). 


\section{CONCLUSION}

CasaPound Italy is one of the most interesting and ambiguous populist right-wing extremist groups to emerge in Europe in recent decades (Bartlett et al., 2012). Its supporters say they are not racist-but they oppose immigration because of its impact on wages and housing; claim they are not antisemitic, but anti-Israel vis-à-vis Palestine; not homophobic, but supporters of the "traditional family" (Lidell, 2012). Never before has Italy seen an explicitly neo-fascist group enjoying strategic viability that CasaPound today enjoys. Although CasaPound remains marginal from an electoral point of view, its visibility in the Italian system is symptomatic of the ability of the extreme right to assimilate populist and alternative agendas in order to increase the attractiveness of their policies (Castelli Gattinara \& Froio, 2015).

Like other extremist movements, CasaPound is an example of the tendency in contemporary Europe to play on fears and social crisis in order to advance a right-wing ideology (Gretel Cammelli, 2018). Despite its grassroots nature and extreme ideology, CPI has acquired national relevance and gained international media exposure. In recent years alone, the group opened 94 new local chapters, successfully penetrating mainstream public debates and receiving disproportionate attention by national media. The visibility of CPI's symbols, campaigns, and brand among mainstream audiences is unprecedented for a fringe group so openly inspired by historical fascism (Castelli Gattinara \& Froio, 2020). CPI has also exploited COVID-19, calling the Italian response to the pandemic, "amateurish and partisan" (Willson, 2020).

In the closing sentences of his essay titled "Ur-Fascism" published in the New York Review of Books, Umberto Eco (1995) warned that "it would be much easier for us if there appeared on the world scene somebody saying: "I want to re-open Auschwitz, I want the Black Shirts to parade again in the Italian squares. Life is not that simple'." The spectre of a new fascism currently haunts Italy_and Europe_-but is not readily identifiable in the black-shirted urban and rural spectacles of CasaPound. It is alarming to see that a survey by Censis research institute showed 48.2 percent of Italians are in favour of having a "strongman" in power who does not care about parliament and elections, while a poll by Demos in November 2017 revealed that almost 60 percent of Italians were "very worried about the rise of fascism" (Bialasiewicz \& Stallone, 2020). 


\section{REFERENCES}

- (2011). "City of Helsinki rented space to neo-Nazi group." YLE News. October 10, 2011. https://yle.fi/uutiset/osasto/news/city_of_helsinki_rented_space_to_neo-nazi_ group/5445909 (accessed on May 31, 2021).

- (2019). "Migration and migrant population statistics." Eurostat. https://ec.europa.eu/eurostat/statistics-explained/index.php/Migration_and_migrant_population_statistics (accessed on May 4, 2021).

- (2019). "Roma woman gets rape threat amid protest." ANSA. May 7, 2019. https://www. ansa.it/english/news/general_news/2019/05/07/roma-woman-gets-rape-threat-amidprotest_032c0576-87e4-4df6-9f62-5dc6be4d5012.html (accessed on May 4, 2021).

- (2020). "Facebook v. CasaPound." Global Freedom of Expression / Columbia University. April 29, 2020. https://globalfreedomofexpression.columbia.edu/cases/casapound-v-facebook/ (accessed on May 5, 2021).

- (2020). "Italian judge orders seizure of neo-fascist CasaPound headquarters." Reuters. June 4, 2020. https://www.reuters.com/article/us-italy-politics-neofascists-idUSKBN23B2OW (accessed on May 5, 2021).

Albanese, Matteo; Bulli, Giorgia; Castelli Gattinara, Pietro \& Froio Caterina. (2014). Fascisti di un altro millennio? Crisi e partecipazione in CasaPound Italia. Acireale/Roma: Bonanno Editore.

Albertazzi, Daniele \& McDonnell, Duncan. (2005). "The Lega Nord in the second Berlusconi government: In a league of its own". West European Politics. 28 (5), pp. 952-972.

Amante, Angelo. (2019). "Half of Italians want 'strongman' in power, survey shows." Reuters. December 6, 2019. https://www.reuters.com/article/us-italy-politics-survey-idUSKBNTYATX5 (accessed on May 31, 2021).

Aminzade, Ronald \& McAdam, Doug. (2001). "Emotions and Contentious Politics." In: Silence and Voice in the Study of Contentious Politics. Eds. Ronald Aminzade, Jack A. Goldstone, Doug McAdam, Elizabeth J. Perry, William H. Sewell, Sindey Tarrow, and Charles Tilly. 14-50. Cambridge: Cambridge University Press.

Atkinson, J., \& Berg, S. (2016). "Right wing activism: The next challenge for alternative media scholarship." In: T. Hug \& W. Sützl (Eds.). Activist media and biopolitics: Critical media interventions in the age of biopower. (pp. 117-133). Innsbruck university press: Innsbruck.

Barnes, David. (2019). "Going back somewhere: nostalgia and the radical right." Open Democracy. August 6, 2019. https://www.opendemocracy.net/en/countering-radical-right/ going-back-somewhere-nostalgia-and-radical-right/ (accessed on May 5, 2021).

Bartlett, Jamie; Birdwell, Jonathan \& Froio, Caterina. (2012). "Populism in Europe: CasaPound." DEMOS. October 2012. https://www.opensocietyfoundations.org/publications/populism-europe-casapound-italy (accessd on May 5, 2021).

Ben-Ghiat, Ruth. (1996). "Italian Fascism and the aesthetics of the 'Third Way'." Journal of Contemporary History. Vol. 31, no. 2, 293-316.

Bialasiewicz, Luiza, \& Stallone, Sabrina. (2020). "Focalizing new-Fascism: Right politics and integralisms in contemporary Italy." Environment and Planning. C, Politics and Space.

38(3), 423-442. https://doi.org/10.1177/2399654419871303 
Bjorgo, Tore \& Witte, Rob. (1993). Racist Violence in Europe. New York: St. Martin's Press.

Bjorgo, Tore. (1995). Terror from the Extreme Right. London: Frank Cass.

Bjørkelo, Kristian A. (2015). “The New Fascists.” Hate Speech International. January 27, 2015.

Blinkhorn, Martin. (2000). Fascism and the Right in Europe 1919-1945. Harlow, UK: Longman.

Boomgaarden, H. G., \& Vliegenthart, R. (2007). "Explaining the rise of anti-immigrant parties: The role of news media content." Electoral Studies. 26(2), 404-417. doi:10.1016/j.electstud.2006.10.018

Bosi, Lorenzo \& Zamponi, Lorenzo. (2015). "Direct Social Actions and Economic Crises: The Relationship between Forms of Action and Socio-Economic Context in Italy." Partecipazione e Conflitto. 8(2): 367-391.

Brioni, Simone. (2017). "A station in motion: Termini as heterotopia." Italian Studies. 72(3): 443-454.

Bulli, Giorgia. (2019). "CasaPound Italia's cultural imaginary." Patterns of Prejudice. 53(3). 253-269. https://doi.org/10.1080/0031322X.2019.1595465

Castelli Gattinara, Pietro; Froio, Caterina; Albanese, Matteo. (2013). "The appeal of neo-fascism in times of crisis. The experience of CasaPound Italia." Fascism (Leiden). 2(2), 234-258. https://doi.org/10.1163/22116257-00202007

Castelli Gattinara, Pietro \& Froio, Caterina. (2014). "Discourse and Practice of Violence in the Italian Extreme Right: Frames, Symbols, and Identity-Building in CasaPound Italia." International Journal of Conflict and Violence. 8(1), 154-170.

Castelli Gattinara, Pietro \& Froio, Caterina. (2015). "Neo-fascist mobilization in contemporary Italy. Ideology and repertoire of action of CasaPound Italia." Journal for Deradicalization. $1(2), 86-118$.

Castelli Gattinara, Pietro \& Froio, Caterina. (2016). "Direct Social Actions in Extreme Right Mobilisations: Ideological, Strategic and Organisational Incentives in the Italian Neo-Fascist Right." Partecipazione e conflitto. 9, no. 3: 1040-1066.

Castelli Gattinara, Pietro. (2017). "Framing exclusion in the public sphere: Far-right mobilisation and the debate on Charlie Hebdo in Italy." South European Society and Politics. 22(3), 345-364.

Castelli Gattinara, Pietro \& Froio, Caterina. (2019). "Why Italy's media fixates on CasaPound, an extreme-right party with a racist agenda." Monkey Cage/Washington Post. May 28, 2019. https://www.washingtonpost.com/politics/2019/05/28/why-italys-media-fixates-casapound-an-extreme-right-party-with-racist-agenda/ (accessed on May 4, 2021).

Castelli Gattinara, Pietro \& Bouron, Samuel. (2020). "Extreme-right communication in Italy and France: political culture and media practices in CasaPound Italia and Les Identitaires." Information, Communication \& Society. 23(12), 1805-1819. https://doi.org/10.1080/136911 $\underline{8 X .2019 .1631370}$

Castelli Gattinara, Pietro \& Froio, Caterina. (2020). "CasaPound Italia: Contemporary Extreme Right Politics." C-REX. April 27, 2020. https://www.sv.uio.no/c-rex/english/news-andevents/right-now/2020/2020-03-casapound-italia-contemporary-extreme-right.html (accessed on May 4, 2021). 
Castriota, Anna \& Feldman, Matthew. (2014). "'Fascism for the Third Millennium': an overview of language and ideology in Italy's CasaPound movement." In: Matthew Feldman and Paul Jackson. Doublespeak: The Rhetoric of the Far Right since 1945. Stuttgart: ibidemVerlag, 223-246.

De Genova, N. (2013). "Spectacles of migrant 'illegality': The scene of exclusion, the obscene of inclusion." Ethnic and Racial Studies. 36(7): 1180-1198.

Della Porta, Donatella \& Diani, Mario. (2006). Social Movements: An Introduction. Oxford: Blackwell Publishing.

Della Porta, Donatella. (2013). Clandestine Political Violence. New York: Cambridge University Press.

Durham, Martin. (1998). Women and Fascism. Routledge. ISBN 10: 0415122805 / ISBN 13: 9780415122801

Eco, Umberto. (1995). “Ur-Fascism.” The New York Review of Books. June 22, 1995.

Ellinas, A. (2010). The media and the far right in Western Europe: Playing the nationalist card. Cambridge: Cambridge University Press.

Esser, Frank. (2013). "Mediatization as a challenge: Media logic versus political logic." In: H. Kriesi (Ed.). Democracy in the age of globalization and mediatization. pp. 155-176. Basingstoke: Palgrave.

Eyerman, Ron \& Jamison, Andrew. (1991). Social Movements: A Cognitive Approach. Cambridge: Polity.

Feldman, Matthew. (2013). Ezra Pound's Fascist Propaganda, 1935-45. Basingstoke: Palgrave.

Forchtner, Bernhard \& Kølvraa, Christoffer. (2017). "Extreme right images of radical authenticity: multimodal aesthetics of history, nature, and gender roles in social media." European Journal of Cultural and Political Sociology. Vol. 4, no. 3, 252-81.

Gentile, Giovanni. ([1927] 2001). "Origini e dottrina del fascismo." In: L'Autobiografia del fascismo. Antologia dei Testi Fascisti 1919-1945. Edited by Renzo De Felice. 247-271.

Gentile, Giovanni. (1934). Origini e dottrina del fascismo. Rome: Libreria del Littorio.

Giuffrida, Angela. (2019). "Court tells Facebook to reactivate Italian neo-fascist party's account." The Guardian. December 12, 2019. https://www.theguardian.com/world/2019/dec/12/ court-tells-facebook-reactivate-italian-neo-fascist-party-account-casapound (accessed on May 4, 2021).

Goodwin, Jeff; Jasper, James M. \& Polletta, Francesca. (2001). Passionate Politics: Emotions and Social Movements. Chicago: University of Chicago Press.

Goodwin, Jeff. (2004). "What Must We Explain to Explain Terrorism?" Social Movement Studies. 3:259-65.

Gretel Cammelli, Maddalena. (2014). Millenial Fascism. Contribution à une Anthropologie du Fascisme du Troisième Millénaire. PhD diss. Ecole des Hautes Etudes en Sciences Sociales, Paris.

Gretel Cammelli, Maddalena. (2017b). "Fascism as a Style of Life: Community Life and Violence in a Neo-fascist Movement in Italy." Focaal - Journal of Global and Historical Anthro- 
pology. 79: 89-101.

Gretel Cammelli, Maddalena. (2018). "The legacy of fascism in the present: "third millennium fascists in Italy." Journal of Modern Italian Studies. 23(2), 199-214. https://doi.org/10.1080/ 1354571X.2018.1427952

Holmes, D. (2000). Integral Europe: Fast-capitalism, multiculturalism, neofascism. Princeton, NJ: Princeton University Press.

Horowitz, Jason. (2017). "In Italy, a Neo-Fascist Party's Small Win Creates Big Unease." The New York Times. November 17, 2017. https://www.nytimes.com/2017/11/17/world/europe/ casapound-italy-neo-fascist-party.html?action=click\&module=RelatedCoverage\&pgtype=Article\&region=Footer (accessed on May 4, 2021).

Jones, Tobias. (2018). "The fascist movement that has brought Mussolini back to the mainstream." The Guardian.February 22, 2018. https://www.theguardian.com/news/2018/feb/22/ casapound-italy-mussolini-fascism-mainstream (accessed on May 4, 2021).

Kington, Tom. (2011). "Ezra Pound's daughter aims to stop Italian fascist group using father's name." The Guardian. December 23, 2011. https://www.theguardian.com/world/2011/ dec/23/ezra-pound-daughter-italian-fascist (accessed on May 4, 2021).

Kington, Tom. (2011a). "Italy's fascists stay true to Mussolini's ideology." The Guardian. November 6, 2011. https://www.theguardian.com/world/2011/nov/06/italy-fascists-true-mussolini-ideology (accessed on May 4, 2021).

Kington, Tom. (2012). "Ezra Pound's daughter fights to wrest the renegade poet's legacy from fascists." The Guardian. January 14, 2012. https:/www.theguardian.com/world/2012/ jan/14/ezra-pound-daughter-fascism (accessed on May 4, 2021).

Kington, Tom. (2013). "Benito Mussolini: a dictator for all seasons in Italy?" The Guardian. January 1, 2013. https://www.theguardian.com/world/2013/jan/01/benito-mussolini-rehabilitation-italy (accessed on May 4, 2021).

Koch, Heiko. (2013). Casa Pound Italia: Mussolinis Erben. Münster: Unrast Verlag.

Koopmans, Ruud \& Olzak, Simon. (2004). "Discursive Opportunities and the Evolution of Right-Wing Violence in Germany." American Journal of Sociology. 110 (1): 198-230.

Liddell, C. (2012). "In the house of pound." The Magazine. February 5, 2012.

Lubbers, Marcel. (2001). Exclusionistic Electorates. Extreme right-wing voting in Western Europe. Nijmegen: KUN/ICS.

Lupo, Salvatore. (2005). II fascismo: La politica di un regime totalitario. Rome: Donzelli.

Mammone, Andrea. (2008). "The transnational reaction to 1968: Neo-Fascists Fronts and political cultures in France and Italy." Contemporary European History. 17: 213-236.

Mammone, Andrea. (2009). "The Eternal Return? Faux Populism and Contemporization of Neo-Fascism across Britain, France and Italy." Journal of Contemporary European Studies. 17, no. 2.

Mammone, Andrea. (2015). Transnational Neo-Fascism in France and Italy. Cambridge: Cambridge University Press.

Mangan, John A. (1999). "Global Fascism and the Male Body: Ambitions, Similarities and Dissimilarities." International Journal of History of Sport. 16 (4): 1-26. 
Miller-Idriss, Cynthia. (2018). The Extreme Gone Mainstream: Commercialization and Far Right Youth Culture in Germany. Princeton, NJ and Oxford: Princeton University Press.

Minkenberg, Michael. (2001). "The Radical Right in Public Office: Agenda-setting and Policy Effects." West European Politics. 24(4), pp. 1-21.

Mosse, George L. (1996). "Fascist Aesthetics and Society: Some Considerations." Journal of Contemporary History. 31 (2): 245-52.

Mudde, Cas. (2007). Populist radical right parties in Europe. Cambridge; New York, UK: Cambridge University Press.

O'Boyle, Christopher G. (2002). “Theories of Justification and Political Violence: Examples from Four Groups."Terrorism and Political Violence. 14 (2): 23-46.

O'Connell, John M. \& Castelo-Branco, Salwa. E. (2010). Music and Conflict. Chicago: University of Illinois Press.

Olzak, Susan \& Shanahan, Suzanne. (1996). "Deprivation and Race Riots: An Extension of Spilerman's Analysis." Social Forces. 74(3), pp. 931-961.

Payne, Stanley G. (1996). A History of Fascism 1914-1945. Madison: University of Wisconsin Press.

Pirrò, Andrea \& Castelli Gattinara, Pietro. (2018). "Movement parties of the far right: The organization and strategies of nativist collective actors." Mobilization: An International Quarterly. 23(3), 367-383. doi:10.17813/1086-671x-23-3-367

Pound, Ezra. (1985). I Cantos. Milano: Arnaldo Monadori.

Povoledo, Elisabetta. (2018). "Anti-Fascist Protesters Rally in Italy as Mussolini's Heirs Gain Ground." The New York Times. February 24, 2018. https://www.nytimes.com/2018/02/24/ world/europe/italy-elections-violence.html (accessed on May 4, 2021).

Provost, Claire \& Whyte, Lara. (2018). "Why are women joining far-right movements, and why are we so surprised?" Open Democracy. January 31, 2018. https://www.opendemocracy.net/en/5050/women-far-right-movements-why-are-we-surprised/ (accessed on May 5, 2021).

Pruijt, Hans. (2013). "The logic of urban squatting." International Journal of Urban and Regional Research. Vol. 37, no. 1, 19-45.

Redman, Tim. (1991). Ezra Pound and Italian Fascism. New York: Cambridge University Press.

Reisigl, Martin. (2008). "Analyzing political rhetoric." In: Ruth Wodak and Michał Krzyżanowski (eds). Qualitative Discourse Analysis in the Social Sciences. Basingstoke and New York: Palgrave Macmillan, 96-120.

Rinaldi, Andrea \& Feldman, Matthew. (2015). "'Pennywise...': Ezra Pound's Posthumous Legacy to Fascism." Sanglap: Journal of Literary and Cultural Inquiry. 1, no. 2 (2015): 27-70.

Roberts, Hannah. (2020). “The 'second liberation' of Rome." Politico. June 24, 2020. https:// www.politico.eu/article/second-liberation-of-rome-far-right-casapound/ (accessed on May $5,2021)$.

Scianca, Adriano. (2011). Riprendersi Tutto: le parole di CasaPound: 40 concetti per una rivoluzione in atto. Milan: Società Editrice Barbarossa. 
Selmini, Rossella. (2016). "Ethnic Conflicts and Riots in Italy: The Case of Rome, 2014." European Journal of Criminology. 13 (5): 626-638.

Staff, Harriet. (2012). "Ezra Pound's daughter sues Italian fascist group CasaPound." Poetry News. January 2, 2012. www.poetryfoundation.org/harriet/2012/01/ezra-pounds-daughtersues-italian-fascist-group-casapound// (accessed on May 27, 2021).

Stolcke, Verena. (1995). "Talking Culture: New Boundaries, New Rhetoric of Exclusion in Europe." Current Anthropology. 36 (1): 1-24.

Taggart, Paul. (2000). Populism. New York: Open University Press.

Tarchi, Marco. (2003). Fascismo: teorie, interpretazioni e modelli. Rome and Bari: Laterza.

Tondo, Lorenzo. (2019). "Facebook closes Italian neo-fascist party's account." The Guardian. September 9, 2019. https://www.theguardian.com/world/2019/sep/09/facebook-closes-italian-neo-fascist-party-casapound-account (accesseed on May 4, 2021).

Torrisi, Claudia. (2018). "How the Italian media have helped CasaPound 'glamourise' fascism." OpenDemocracy.January 29, 2018. https://www.opendemocracy.net/en/5050/italian-media-casapound-glamourise-fascism/ (accessed on May 4, 2021).

Wieviorka, Michel. (1998). Le Racisme. Une introduction. Paris: La Découverte.

Willson, Richard McNeil. (2020). "Are far right groups really just about spreading conspiracy theories and misinformation?" Open Democracy. September 28, 2020. https://www.opendemocracy.net/en/global-extremes/are-far-right-groups-really-just-about-spreading-conspiracy-theories-and-misinformation/ (accessed on May 5, 2021).

Wolff, Elisabetta Cassina. (2019). "CasaPound Italia: "Back to Believing. The Struggle Continues." Fascism (Leiden).8(1), 61-88. https://doi.org/10.1163/22116257-00801004 


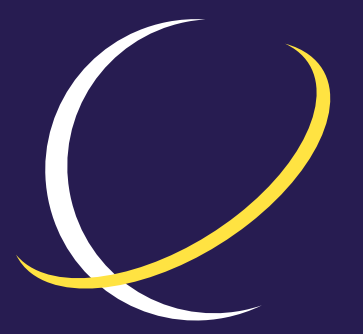

\section{ECPS \\ EUROPEAN CENTER for POPULISM STUDIES}

\section{ABOUT ECPS}

The European Center for Populism Studies (ECPS) is an independent, nonpartisan, nonprofit organization, based in Brussels, for research on and analysis of challenges posed by the resurgence of political populism. ECPS facilitates collaboration among networks of academic experts, practitioners, policymakers, media, and other stakeholders. ECPS offers a platform for the exchange of policy solutions on issues relating to rising populism and provides insights for policy-making and critical analysis to raise broader awareness and engagement through:

\section{Publications}

\section{Academic publications}

Policy reports

White papers

Commentaries

Podcasts and interviews with experts

Events, seminars, workshops, and conferences

\section{Research Programs}

Authoritarianism

Digital Populism

Economics

Environment \& Climate

Extremism \& Radicalisation

Gender

Human Rights

Foreign Policy

Leadership \& Persona

Migration

\section{ECPS Youth Program}

ECPS Academy 